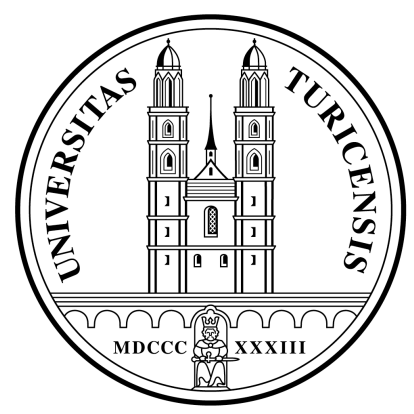

Institute for Empirical Research in Economics

University of Zurich

Working Paper Series

ISSN 1424-0459

Working Paper No. 112

Benefit Entitlement and Unemployment Duration

The Role of Policy Endogeneity

Rafael Lalive and Josef Zweimüller

April 2002 


\title{
Benefit Entitlement and Unemployment Duration The Role of Policy Endogeneity
}

\author{
Rafael Lalive, University of Zurich, IZA, and CESifo * \\ Josef Zweimüller, University of Zurich, IZA, CESifo and CEPR
}

April 2002

\begin{abstract}
The potential duration of benefits is generally viewed as an important determinant of unemployment duration. This paper evaluates a unique policy change that prolonged entitlement to regular unemployment benefits from 30 weeks to a maximum of 209 weeks for elderly individuals in certain regions of Austria. In the evaluation, we explicitly account for the fact that the program was an endogenous policy response to a crisis affecting individuals with severe labor market problems. The main results are: (i) REBP reduced the transition rate to jobs by $17 \%$; (ii) accounting for endogenous policy adoption is important and quantitatively significant.
\end{abstract}

JEL Classification: C41, J64, J65

Keywords: quasi-experiments, policy endogeneity, benefit entitlement, maximum benefit duration, unemployment duration, unemployment insurance

*We are indebted to Jonas Agell, Jim Albrecht, Lorenz Götte, Bertil Holmlund, Brigitte Humer, Georg Kirchsteiger, Francis Kramarz, Michael Lechner, Patrick Puhani, Gerard van den Berg, Jan C. van Ours, Rudolf Winter-Ebmer, and participants of workshops at CEPR, CESifo, Tinbergen Institute, and research seminars at Basel, Geneva, Heidelberg, Oslo, Vienna, and Zurich for valuable comments. We thank Christoph Clavadetscher, Andreas Kuhn, and Florian Stahl for superb research assistance and Maria Hermann for checking the manuscript. Financial support by the Austrian National Bank is gratefully acknowledged. Address: Rafael Lalive, IEW, Bluemlisalpstr. 10, 8006 Zurich, Switzerland, e-mail: rlalive@iew.unizh.ch. Josef Zweimüller, IEW, Bluemlisalpstr. 10, 8006 Zurich, Switzerland, e-mail: zweim@iew.unizh.ch. 


\section{Introduction}

Reliable empirical evidence on the incentive effects of unemployment insurance is crucial for designing appropriate labor market policies. Most empirical studies identify such incentive effects from 'exogenous' variation in benefit rules. However, changes in unemployment insurance rules are, like any other policy choice, purposeful action. In fact, a frequently adopted policy is to extend the maximum duration of benefit entitlement when labor market conditions are expected to deteriorate. Empirical strategies that do not account for the determinants of such policy changes yield biased estimates of the impact of unemployment insurance.

In this paper we evaluate a program that dramatically increased benefit generosity for a specific group of workers: the Austrian Regional Extended Benefits Program (REBP). This program granted an extension of the potential duration of unemployment benefits to older workers in certain regions. The REBP was enacted in response to the international steel crisis that hit the traditional iron and steel regions in Austria particularly hard. The explicit intention of this program was to avoid social hardships for the concerned steel workers and to mitigate problems in the concerned regions. Hence rather than being an 'exogenous' policy change, the REBP was adopted because labor market conditions were expected to become worse. Our analysis will take particular care to account for that 'policy endogeneity'.

The present paper goes beyond most of the existing literature in three respects. First, to identify the causal effect of benefit duration on the willingness of individuals to accept jobs, the REBP provides an unusually rich empirical research design. Access to the program was contingent upon age and region. The program was primarily targeted towards steel workers but also unemployed workers from other sectors were eligible. The program was reformed after being in place over a period of more than three years and this reform excluded several regions because the fears about bad labor market conditions had not come true. The reform also tightened eligibility criteria such that it is possible to compare very similar groups of job-seekers with different eligibility status. The successive policy changes (including the final abolishment) of the REBP allows us to adopt various empirical strategies to account for the endogeneity of the benefit rules and to shed light on the nature of the endogenous policy bias.

Second, the increase in the benefit extension granted by the REBP was huge. It extended benefits for workers above age 50 with residence in certain regions to a maximum of 209 weeks (4 years!), up from originally only 30 weeks. This latter limit for benefit duration puts the Austrian unemployment benefit system closer to the U.S. rules than to many other European countries. And the benefit extension provided by the REBP changed the benefit rules from a rather spartan ('U.S.-style') regime to a rather generous ('European-style') regime. In the U.S. unemployment benefits typically last for at most 26 weeks, whereas in many other European countries unemployment insurance is available for several years. In this sense, our paper sheds new light on the importance of benefit eligibility to explain differences in 
the incidence of long-term unemployment between the U.S. and Europe.

Third, a unique and extraordinary informative data set together with the broad range of policy changes of the REBP allows us to adopt empirical strategies that are not feasible in other studies. Our data set covers the universe of unemployment spells in Austria that started between January 1986 and December 1995. These unemployment spells can be observed up until December 1998. As the REBP was started in June 1988 and abolished in August 1993, the data cover the inflow of approximately 2 $1 / 2$ years before, 5 years during, and 2 1/2 years after the program. The data contain all information that is necessary to determine eligibility status, provide important socio-economic characteristics, and report the work history of individuals. The focus of our analysis is on a comparison of age groups 45-49 and 50-54.

Theoretically, the effect of benefit generosity on unemployment durations is not clear. More generous unemployment insurance tends to decrease the unemployment exit rate at the start of the spell ("disincentive effect") but may increase the hazard rate at a later stage ("entitlement effect"). ${ }^{1}$ However, the vast majority of empirical studies has found that increasing the maximum duration of unemployment benefits tends to prolong average unemployment duration. Katz and Meyer (1990) estimate an increase in unemployment duration of .16 to .20 weeks per additional week of potential benefit duration. This is close to the findings of other U.S. studies (Moffitt and Nicholson (1982) and Moffitt (1985). Ham and Rea (1987) report a somewhat larger result for Canada; Hunt (1995) and Bratberg and Vaage (2000) find a similar effect, respectively, for Germany and for Norway, whereas Winter-Ebmer (1998) estimates a smaller impact for Austria. ${ }^{2}$

These previous studies identify the impact of extended benefits from variation in benefit entitlement across time, states, and/or age groups. In the U.S., for instance, the Extended Benefit Program grants unemployed individuals up to 13 additional weeks of benefits during periods of high unemployment; also in Canada the duration of benefit entitlement to unemployment benefits depends on the current regional unemployment situation; in Austria, Germany, and Switzerland benefit durations have been increased in several steps, in particular for older individuals, since the mid 1980s and/or early 1990s and these increases were to a large extent motivated by the deteriorating labor market prospects of the respective groups.

Typically the reasons for changes in benefit rules are not accounted for and the empirical strategies of

\footnotetext{
${ }^{1}$ See Burdett (1979), Mortensen (1977), and Van den Berg (1990) for theoretical analyses. An early review of the effect of unemployment insurance on labor market transitions is Atkinson and Micklewright (1991).

${ }^{2}$ Other recent studies that shed light on the importance of benefit eligibility compare between receivers and nonreceivers of unemployment benefits (Carling et al. (1996) for Sweden and Bover et al. (1998) for Spain); or study major cuts in benefits (e.g. Carling et al. (1999) look at a major benefit cut in Sweden and Abbring et al. (1998) and Van den Berg et al. (2002) look at the impact of major benefit cuts due to sanctions in the Netherlands) or re-employment cash bonuses (see the survey on the U.S. unemployment insurance experiments in Meyer (1995b)).
} 
these previous studies suffer from the policy endogeneity problem. ${ }^{3}$ When benefit policy is determined by labor market conditions, observed changes in unemployment duration are only in part due to changes in entitlement rules. They are also due to changes in labor market conditions that lead to new benefit rules in the first place. Hence, not accounting for policy endogeneity leads most likely to biased estimates of the causal impact of benefit generosity on unemployment duration.

Like other extended benefit programs, the Austrian REBP was an endogenous policy response to the expectation of deteriorating labor market conditions. In order to disentangle the causal effect of benefit entitlement from the impact of labor market conditions we adopt four different identification strategies. The first strategy performs a simple differences-in-differences-in-differences (DiDiD) analysis exploiting variation in the maximum benefit durations that occurs between regions, time, and age groups. ${ }^{4}$ The identifying assumption is that there are no labor market shocks specific to age and region. We will argue that this assumption is unlikely to be satisfied as the program was targeted towards older workers in certain regions who were expected to suffer from specific shocks.

The second strategy confines the analysis to non-steel workers. This analysis should be less afflicted with the policy endogeneity bias as non-steel workers were not directly subject to specific shocks. The problem with this strategy is that there might be indirect effects if there are strong sectoral linkages within the region.

Our third strategy takes the importance of indirect effects into account. We focus on those treated regions that lost eligibility status with the reform of the REBP in 1991. For these regions, the expectation of worse labor market conditions had not come true. Under the assumption that labor market conditions do not depend on the treatment status of a region, the causal impact of the program can be identified.

Our final strategy makes use of the changes in the eligibility criteria with the reform of the REBP in 1991. After this reform, eligibility required that an older worker had not only to be a resident in a REBP region, but also the location of the previous employer had to be in such a region. Hence, we can compare two interesting groups of individuals: The first group was previously resident and employed in a treated region. The second group was resident but not previously employed in such a region. Both groups were eligible before the reform, but only the first group was also eligible after the reform. Under the assumption that labor market conditions did not differ between these two groups the causal impact of the benefit extension can be identified.

\footnotetext{
${ }^{3}$ See Besley and Case (1994) or Meyer (1995a) for a discussion of policy endogeneity in 'natural or quasi experiment' studies.

${ }^{4}$ An alternative approach would be to use a 'regression-discontinuity' design by comparing unemployment duration for those just younger than 50 years of age to unemployment duration of those just older than 50 years of age (Angrist and Krueger, 1999). However, in using this design, one does discard valuable information on the development of the labor market in the control regions.
} 
The recent literature dealing with the impact of benefit entitlement rules on unemployment durations has largely ignored the issue of policy endogeneity. An important exception is the paper by Card and Levine (2000) who study the impact of the New Jersey Extended Benefit Program. This program was initiated as a result of a political deal between the state government and the labor organizations rather than by a depressed job market. Most importantly, this increase in benefits was enacted during a period of improving labor market conditions. Hence, Card and Levine's analysis does not suffer from an endogenous policy bias. Moreover, the effect of the New Jersey Extended Benefit Program on unemployment durations turns out to be much smaller than found in other studies pointing to potentially significant biases in studies that do not account for endogenous policy adoption.

The study by Card and Levine (2000) differs from our analysis in at least three important respects. First, the New Jersey Extended Benefit Program (NJEB) was in place for only 6 months, thus it is difficult to identify the long-term effects of the benefit extension. In contrast, the Austrian REBP was a long-term program that was in effect over a period of five years and provides an ideal set-up to study the long-term effects of the program. Second, the NJEB program granted a moderate benefit extension of 13 additional weeks of regular unemployment benefits. This compares to 179 (!) extra benefit weeks granted by the Austrian REBP. This huge benefit extension offers the unique opportunity to study a change in rules equivalent to the typical U.S.-European differential. Furthermore, Card and Levine (2000) can neglect the policy endogeneity issue as the NJEB program was not targeted towards a group with bad labor market prospects. In contrast, the endogenous policy issue is central for the Austrian REBP as this program was intended to help workers confronted with an unfavorable conditions job market. Our paper shows that, despite this policy endogeneity problem, it is possible to estimate the causal impact of extended benefits on the transition rate from unemployment to a regular job.

The only previous study that has so far analyzed the impact of the Austrian REBP is a paper by Winter-Ebmer (1998) who looks at the initial impact of the benefit extension. The present paper goes beyond this study in a number of ways. First, we put particular emphasis on the problem of policy endogeneity and provide an empirical test that accounts for this issue. Second, we consider not only the impact of the benefit extension after its introduction, but also the impact of the reform and of the abolishment of the REBP. Third, we use a more informative and much larger data set. This allows us to focus on a narrow age group and avoid a possible bias resulting from a misspecification of the effect of age. Fourth, we confine the analysis to male workers and exclude females. The reason is that females had access to early retirement with age 55 and, for females, the REBP effectively allowed women to withdraw from the labor force.

The paper is organized as follows. In Section 2 we provide some information on the Austrian labor market, survey the Austrian unemployment insurance system, and give a detailed description of the Austrian REBP. Section 3 deals with issues regarding identification and Section 4 describes the data 
and presents the econometric model. In Section 5 we present the results and Section 6 concludes.

\section{Austrian Unemployment Insurance and the REBP}

This section discusses first the details of the Austrian unemployment insurance system. Then, we describe the benefit entitlement rules of the REBP. The section closes with a first look at aggregate data on Austrian unemployment before and after REBP was enacted.

The Unemployment Insurance System Before August 1989 regular unemployment benefits (UB) were received by an unemployed person for a period that depended, exclusively, on previous work experience. The maximum duration of UB was 30 weeks provided that the unemployed had paid unemployment insurance contributions for at least 156 weeks within the last 5 years. ${ }^{5}$ In August 1989 the potential duration of UB payments became dependent not only on previous experience but also on age at the beginning of the unemployment spell. Benefit duration for the age group 40-49 was increased to 39 weeks if the unemployed has been employed 312 weeks of employment within the last 10 years prior to the current spell. For the age group 50 and older, UB-duration was increased to 52 weeks if the unemployed has been employed for at least 468 weeks within the last 15 years. Our empirical analysis below controls for the general change in benefit duration. ${ }^{6}$

Voluntary quitters and workers discharged for misconduct can not claim benefits until a waiting period of 4 weeks has passed. UB recipients are expected to search actively for a new job which should be within the scope of the claimant's qualifications, at least during the first months of the unemployment spell. Non-compliance with the eligibility rules is subject to benefit sanctions that can lead to withdrawal benefits for up to 4 weeks.

Compared to other European countries, the replacement ratio (UB relative to gross monthly earnings) is rather low. The amount of UB payments depends on previous earnings and, in 1990, the replacement ratio was $40.4 \%$ for the median income earner; $48.2 \%$ for a low-wage worker who earned half the median; and $29.6 \%$ for a high-wage worker earning twice the median. On top of this, family allowances are paid. UB payments are not taxed and not means-tested. There is no experience rating.

After UB payments have been exhausted, job seekers can apply for 'transfer payments for those in need' ("Notstandshilfe"). ${ }^{7}$ As the name indicates, "transfer payments for those in need" are meanstested and the job seeker is considered to be eligible only if she or he is in trouble. These payments depend on the income and wealth situation of other family members and close relatives and may, in

\footnotetext{
${ }^{5}$ UB duration was 20 weeks for job-seekers who did not meet this requirement. This paper focuses on individuals who were entitled to at least 30 weeks of benefits.

${ }^{6}$ Note that the causal effect of this general increase in benefit eligibility is identified only if the implausible assumption of temporal stability in the unemployment exit rate holds.

${ }^{7}$ This implies that job seekers who do not meet UB eligibility criteria can apply at the beginning of their spell
} 
principle, last for an indefinite time period. These transfers are granted for successive periods of 39 weeks after which eligibility requirements are recurrently checked.

The post-UB transfers are lower than UB and can at most be $92 \%$ of UB. In 1990, the median post-UB transfer payment was about $70 \%$ of the median UB. Note however, that individuals who are eligible for such transfers may not be comparable to individuals who collect UB because not all individuals who exhaust UB pass the means test. The majority of the unemployed (59\%) received UB whereas $26 \%$ received post-UB transfers.

In sum, the Austrian unemployment insurance system is less generous than many other continental European systems and closer to the U.S. system (Nickell and Layard, 1999). Until 1989, regular unemployment benefits did not last much longer than in the U.S. and the replacement rate was comparable to U.S. levels. Note that also in the U.S. there are means-tested post-UB transfers and, for certain groups, these transfers can reach levels close to regular UBs, whereas for other groups such benefits are available only to a very limited extent. ${ }^{8}$

The Regional Extended Benefit Program (REBP) In June 1988, the Austrian government enacted a law that extended UB-entitlement to 209 weeks for a specific subgroup. This group consisted of individuals considered to suffer most heavily from the adverse labor market consequences of the international steel crisis. The crisis hit certain regions of the Austrian economy, in particular regions where state-owned firms were located. The measure was intended to help also employees in other industries that were indirectly affected by the crisis and the restructuring process that was initiated in many nationalized firms thereafter (Hesoun, 1988).

An unemployed worker became eligible to 209 weeks of UB if he or she satisfied, at the beginning of his or her unemployment spell, each of the following criteria: (i) age 50 or older; (ii) a continuous work history (780 employment weeks during the last 25 years prior to the current unemployment spell); (iii) location of residence in one of 28 selected labor market districts since at least 6 months prior to the claim; and (iv) start of a new unemployment spell after June 1988 or spell in progress in June 1988.

The REBP was in effect until December 1991 when a reform of these rules took place which came into effect in January 1992. This 1991-reform left all claims in progress unaffected. Only new claims were subject to the new rules. The 1991-reform enacted two important changes. First, the reform abolished the benefit extension in 6 of the original 28 regions. The program ended in December 1991 in these districts because the respective labor markets were considered to have improved significantly so that the long UB-entitlement was no longer justified.

\footnotetext{
${ }^{8}$ It is interesting to note that the incidence of long-term unemployment in Austria is closer to U.S. figures than to those of other European countries. In 1995, when our sample period ends, $17.4 \%$ of the unemployment stock were spells with an elapsed duration of 12 months or more. This compares to $9.7 \%$ for the U.S. and to $45.6 \%$ for France, $48.3 \%$ for Germany, and $62.7 \%$ for Italy (OECD, 1995).
} 
The second important change with the 1991-reform was a tightening of the eligibility criteria to extended benefits: new beneficiaries had to be not only residents, but also previously employed in one of the (now only 22) specified regions. The location of the previous employer as an additional eligibility requirement has a quantitatively important impact on the potential number of beneficiaries because a substantial number of residents in REBP-regions were working in a labor market district not covered by the benefit extension (for further details consult Section 5).

A first look at Aggregate Data Austria has been a country with a low unemployment rate and a low average duration of unemployment, as measured by European standards. In 1994, the overall unemployment rate was $6.8 \%$ and the percentage of long-term unemployed ( $\geq 12$ months) was less than $20 \%$, which was much closer to the U.S. figures than to the European average (OECD, 1996).

While Austria has been doing relatively well in terms of unemployment outcomes, the unemployment situation of workers above age 50 has deteriorated dramatically over the period 1988 to 1993 (Figure 1). The unemployment rate of the age group 50 to 59 was $5.1 \%$ in 1988 , which was even below the 1988 overall unemployment rate of $5.3 \%$. After 1988 there was a strong and steady increase in the unemployment rate, reaching a maximum of more than $10 \%$ in 1993 . This is exactly the period during which the REBP was in force. Figure 1 also shows that there was only a moderate upward trend in the unemployment rate of the age group 40-49. This implies that there was a steady increase in the ratio of the unemployment rate of the age group 50-59, relative to the age group 40-49, a trend which did not stop until 1993, when the law was abolished. Moreover, this increase in the relative unemployment rate was almost exactly matched by an increase in the relative incidence of long-term unemployment.

Figure 1

\section{Identification}

This section discusses four strategies to identify the causal effect of the benefit extension provided via the REBP on unemployment duration. The causal effect of benefits on unemployment duration is defined as the change in the unemployment exit rate due to the REBP for a particular worker. In order to estimate this effect, it is necessary to identify the counterfactual, i.e. the unemployment exit rate of the job seekers entitled to the REBP in the case they had not received treatment. ${ }^{9}$

Strategy I: The DiDiD Estimator The fact that the REBP was limited to job seekers aged 50 or more, living in certain regions, during the period from June 1988 until mid 1993 implies that there are many non-entitled workers who may be quite similar to entitled individuals. The central idea in this first strategy exploits all information provided by potential control groups.

\footnotetext{
${ }^{9}$ Note that we use the term treatment to indicate that an individual is entitled to REBP.
} 
For instance, the simplest estimate of the REBP-effect involves a comparison of the unemployment exit rate of entitled workers during the program to the level before the program. This is problematic because there may have been an economic downturn leading to an overestimation of the effect of the REBP on unemployment duration. In order to account for such a time trend, the unemployment exit rate of individuals slightly younger than 50 living in entitled regions can be used. Still, this may be problematic in the case of a changing age-specific hiring bias: It may be possible that employers become increasingly reluctant to hire individuals older than 50 as opposed to individuals just below the age of 50. This possibility can be controlled for by using data on individuals living in regions that were not entitled to the REBP. In essence, it appears thus to be possible to account for time-trends in the unemployment exit rate as well as age-specific trends in the employment chances of individuals. Section 5 performs this DiDiD analysis.

The central identifying assumption is that the time trend in the unemployment exit rate as well as the age-specific time trend identified in the non-treated group are informative on the counterfactual. This means that there must be no idiosyncratic shocks to the labor market prospects of the treated individuals during the period when the REBP was in effect. This is equivalent to saying that there was no policy endogeneity.

Table 1 shows that there may indeed be arguments in favor of the simple DiDiD strategy. The table reports the average unemployment rate and the average percentage long-term unemployed individuals in the year before the REBP was enacted. The table also distinguishes between treated regions and control regions, and between individuals aged 45-49 and individuals aged 50-54. The unemployment rate was $4.0 \%$ in treated regions for individuals aged 50-54, almost the same as the unemployment rate for those aged 45-49 (3.6\%). In control regions, we observe a slightly higher level of the unemployment rate for the group aged 50-54 (4.9\%), and almost identical unemployment rate for those aged 45-49 (4.0 $\%)$. With respect to long-term unemployment, there are differences between the age groups. In treated regions, the percentage of long-term unemployed individuals is higher by 6.6 percentage points in the group aged 50-54 compared to the age group 45-49. However, note that this difference is the same in control regions. Thus, while these groups are not comparable in levels, the difference with respect to age across regions is very similar before the program. Hence, ex ante the four groups seem to be very similar with respect to their labor market performance. This evidence suggests that information on unemployed individuals below the age of 50 and on those living in control regions may be useful to approximate the counterfactual outcome of non-treatment for the eligible group. Note that the idea of comparing the treated group with the non-treated group before the treatment is the so-called 'pre-program test' put forward in the evaluation literature in the case of panel data (Heckman and Hotz, 1989).

Table 1 
Strategy II: Excluding steel workers After World War II the Austrian steel sector was nationalized in order to protect this industry from serving as German war repatriation. By the 1980s this industry was characterized by low productivity, low investment in research and development activities, accumulated substantial losses, and was dependent on large subsidies. Moreover, in the early 1980s the steel sector was hit by a severe drop in the world market price of steel products and it became clear that the steel sector had to undergo major restructuring. The REBP was part of this restructuring plan by rendering it easier to lay off older workers. Thus, one likely reaction of steel firms was to cut back on hiring older workers more strongly than younger workers in the period when the REBP was in effect because this period happened to coincide with the steel sector restructuring. Of course, such a hiring policy will directly violate the identifying assumption of Strategy I because there may be a hiring bias during the REBP-period against treated workers. ${ }^{10}$

To what extent did the crisis cause worse labor market prospects for older steel workers in the treated regions? Table 2 gives a tentative answer to this question by showing average completed unemployment duration, and the percentage of individuals that exit to a regular job. These statistics are reported separately for individuals previously employed in the steel industry and non-steel workers, as well as for treated and non-treated spells. ${ }^{11}$ This table shows that steel workers have in fact done much worse than non-steel workers. The average duration of a completed unemployment spell is almost twice as long for a steel worker as compared to a worker previously employed in a different industry. Steel workers in the age group 45-54 are less likely to reenter employment: only $66 \%$ of spells suffered by steel workers end in a transition to a new job, as opposed to $85 \%$ of spells by workers from other industries. Moreover, the difference between treated spells and non-treated spells in the percentage of spells ever ending in a regular job is as large as 40 percentage points for steel workers whereas the corresponding gap is only 12 percentage points for non-steel workers.

Table 2

The evidence in Table 2 suggests that steel workers might have been hit by a severe drop in demand during the period when the REBP was in effect. ${ }^{12}$ This violates the identifying assumption of Strategy

\footnotetext{
${ }^{10} \mathrm{~A}$ second reason why the identifying assumption in Strategy I may be violated is that the job separation rate might have been affected by REBP (Winter-Ebmer, 2002). Note, however, that if firms fire the least productive workers first, an increase in the separation rate implies that the average quality of the unemployment pool is higher in the treated regions. As better workers have better chances to get a new job, we underestimate the program effect by not accounting for the selectivity of the unemployment pool. Moreover, the effect of REBP on job separations is greatly reduced by omitting steel workers (Lalive and Zweimüller, 2002).

${ }^{11}$ These statistics are based on the dataset that is described in Section 4 . Treated spells satsify all REBP eligibility criteria mentioned in Section 2.

${ }^{12}$ In order to assess the validity of the identifying assumption of Strategy I, we have to assume that the causal effect of extended benefits is identical for steel and non-steel workers. This assumption is likely to hold (conditional on observe characteristics) because unemployment benefits do not depend on previous industry.
} 
I. Indeed, the policy was motivated by the fact that one should provide sufficient protection to elderly individuals previously employed in the steel sector (Hesoun, 1988).

The second identification strategy takes into account that workers formerly employed in the steel sector may cause the identifying assumption in Strategy I to be violated. A possible way to take care for this source of bias is to exclude these workers from the analysis. With this procedure we disregard unemployment spells for which the identifying assumption required for the $\mathrm{DiDiD}$ analysis is not satisfied.

The second strategy identifies the causal effect of the REBP on unemployment duration if and only if there are no idiosyncratic shocks to treated workers not previously employed in the steel sector. This is the case if there are no age-specific spillovers from the steel sector to other sectors in the treated regions.

\section{Strategy III: Treated regions with favorable labor market conditions and a small steel} sector The third identification strategy takes the importance of indirect effects into account. The idea of the REBP was to target entire regions with a dominant steel sector, not merely individuals previously employed in the nationalized steel sector of these regions (Hesoun, 1988). The argument was based on the fact that, when a crisis hits a dominant sector within a region, there may be substantial indirect effects on firms in other sectors. Such indirect effects are to be expected, for instance, in sectors which are directly linked with the steel sector either via the factor market (steel serving as an input) or via the product market (industries supplying raw materials or services relevant in the steel production). Moreover, such indirect effects are to be expected via reduced purchasing power of the workers employed in the crisis-ridden steel sector.

Section 2 documents that the REBP was initially granted to 28 regions. Eligibility was then restricted to 22 regions in the reform at the end of 1991. It is thus interesting to ask whether these excluded regions were in some respect different from the set of regions with continuous entitlement. This subsection discusses two important aspects: the size of the steel sector serving as a proxy for the likely indirect repercussions stemming from that sector, and employment growth as a proxy for labor demand within the region.

Table 3 shows that the size of the steel sector has not been the same in all treated regions. We distinguish three types of regions: (i) Control-regions (CR) are those never covered by the REBP; (ii) Treated regions that were covered only during the period 1988 to 1991 and excluded after the 1992reform (TR1 for short); and (iii) Treated regions that were covered throughout the treatment period 1988 - 1993 (TR2). Table 3 shows that employment was strongly concentrated in the steel sector in TR2 regions, on average $19.2 \%$ of the workers were employed by that industry in the year preceding the REBP. However, within TR1 regions, also entitled to the REBP, the steel sector is only slightly larger than in the rest of Austria. The percentage of workers employed in the steel industry was $8.9 \%$ 
in TR1s compared to $4.8 \%$ in CRs. Thus, negative spillovers from the steel sector to other sectors will be substantially smaller within TR1s compared to TR2s.

Table 3

Second, to shed light on the differences in labor market conditions between the various regions, we look at the relative employment dynamics. Figure 2 shows the (unweighted) average employment growth rates before, when, and after the REBP was in effect. (Note that these employment growth rates refer to total employment in the region and not just to older workers.)

\section{Figure 2}

Employment growth in CRs closely reflects the average business cycle conditions over the period 1986 to 1995: employment rose slightly before the law was enacted, rose strongly during the treatment period, and decreased to pre-treatment levels after abolishment. The pattern of fluctuations is similar in the treated regions but their level is quite different. Employment growth rates in TR1s exceeded those in CRs in all years except in 1995. Employment growth rates in TR2s fell short of those in CRs in all years except in 1988 and in 1994.

Table 4 provides several regressions of employment growth rates, and regional job creation and destruction indicators for the period 1981 to 1998. All models include year fixed effects to control for aggregate shocks that affect all regions equally in a given year. The various Columns in Table 4 differ in terms of the specification of regional effects. The regressions in Columns 1, 3, and 5 include an interaction of REBP-status with the treatment period and a (time-invariant) dummy variable coding the REBP-status of a region. The results indicate that in TR1s employment growth during the treatment period has not been significantly different from employment growth in the entire 1981-1998 period. Over this entire period TR1s showed a significantly better employment performance than CRs. In TR2s the situation is quite different. The treatment period 1988 - 1993 for TR2s is significantly worse than the average situation before and after the treatment when there were no significant differences between TR2s and CRs. The results in Column 3 indicate that the worse employment dynamics in the TR2s originates from relatively higher job destruction during the treatment period whereas relative job creation (Column 5) during treatment does not differ significantly from the period before and after the treatment.

Table 4

Columns 2, 4, and 6 include regional fixed effects that absorb region-specific permanent differences in labor market conditions over the whole period. We now control not only for REBP-status during the treatment-period 1988 to 1991 but also for this status within the period 1986 to 1995 - the period on 
which our analysis using individual data in Section 5 below will concentrate. The former estimate gives the deviation of the treatment period from the 1986 - 1995 period and equals the difference-in-difference estimate that we report below. The difference-in-difference estimate in Table 4 Column 2 indicates that the relative employment dynamics of TR1s and CRs during the treatment period 1988-1991 does not differ from the period immediately before and after the treatment. This is not the case for TR2s where relative employment rates are lower and relative job destruction rates are higher during the treatment period 1988 to 1993. In sum, the results in Table 4 suggest that TR2-labor markets did in fact much worse than the non-treated regions, but TR1-labor markets did equally well or even better than control regions.

This analysis documents that TR2 regions were clearly doing worse than control regions. However, TR1s were not afflicted by a downturn in labor demand in the period when the REBP was in effect. The upshot of the two analyses is that (i) indirect effects are likely to be present to the same extent within TR1s as in CRs, and (ii) overall labor demand did not show a decline in the period when the REBP was in effect in TR1s. The third identification strategy exploits this fact by relying on non-steel workers who are not living in TR2 regions. This strategy recognizes both, the fact that the REBP was targeted to older steel workers and the fact that the REBP aimed at alleviating regional spillovers in labor market problems. Because this identification strategy accounts for both potential sources of policy endogeneity bias, we call it the first 'robust' identification strategy. This identification strategy is 'robust' in the sense that the group of treated individuals in this sample is much less likely to have suffered from specific labor market shocks. We have not only excluded non-steel workers from our analysis, but these individuals are also less likely to have suffered from indirect shocks transmitted by the steel crisis: The economic structure in TR1s is very similar to control regions. This identification strategy is further supported by the evidence that, ex post, labor market conditions in TR1s during the treatment period were similar to (or even slightly better than in) control regions. In this sense, our third identification strategy is 'robust'.

This identification strategy is likely to deliver different results compared to the second identification strategy if there are indeed important indirect effects affecting labor market chances of older job seekers in TR2 regions. Moreover, the present identification strategy will show different results from the first identification strategy if either steel workers were hit by a severe downturn or if there are important intra-regional spillovers due to the crisis in the steel sector. The assumption leading to identification of the causal effect is that there were no idiosyncratic shocks to labor demand for treated non-steel workers in TR1.

Given that TR1s were not characterized by a dominant steel sector and that labor demand did not differ from the control regions, why were these regions selected as REBP-treatments in the first place? The government had to make the final decision about which districts to include into the program, and 
this decision was a political one. The government during that election period was a coalition among the two largest parties in the 1986 general election, the social democrats (SPÖ) and the conservative party (ÖVP).

The bottom rows of Table 3 shows two pieces of evidence regarding the political situation in TR1, TR2, and CR that might contribute to explain why TR1 were selected for REBP-entitlement: percentage votes of the social democratic party (SPÖ; the leading party in the coalition) and the conservative party (ÖVP; the smaller coalition party) in the 1986-election; and the home region of the leader of the coalition party ÖVP. First, Table 3 shows that TR2s were dominated by the social democrats (SPÖ), whereas TR1s were dominated by the conservatives (ÖVP). Moreover, the chairman of the conservative party grew up in a TR1. In 1990 and 1991, two successive new chairmen were appointed by the conservative party both of whom did not come from a TR1 region. These figures are consistent with the hypothesis of a political compromise: to get support for the introduction of the REBP in the crisis-ridden (and SPÖ-dominated) TR2s the leading social-democratic party had to concede the REBP-status also to certain labor market districts that were dominated by the conservatives. This kind of lobbying was stronger during the first REBP-period with a party-leader with strong links to TR1s.

Strategy IV: Employment and residence as eligibility criteria The motivation for the last identification strategy is that even if Strategy III delivers different results from the previous two strategies this is not evidence that Strategy III identifies the causal effect of benefit entitlement on unemployment duration. The fact that results change in a strategy based on less restrictive assumptions may merely indicate that the restrictive identifying assumption was violated. Thus, it is essential to think about a second way to identify the causal effect of benefit entitlement on unemployment duration. ${ }^{13}$

The fourth identification strategy is based on the fact that the 1991 reform created an interesting control group for individuals aged 50 or older with residence and previous employment in TR2. As of 1992, entitlement to the REBP was tightened to individuals with residence and previous employment within TR2. Before 1992, entitlement to the REBP was solely dependent on residence in TR2. Thus, individuals older than 50 years of age, previously resident and employed in TR2 were entitled to the REBP from June 1988 until August 1993. This group is referred to as 'the first group'. The 'second group' is also aged 50 or older, resident in TR2 but not previously employed in TR2. This group was entitled to the REBP from June 1988 until December 1991.

The first advantage of this identification strategy is that it is not necessary to rely on individuals below age 50 or individuals living outside of the treated regions to infer the counterfactual. Clearly, this is an important advantage when discussing endogenous policy, targeted to older workers within TR2

\footnotetext{
${ }^{13}$ A second motivation for this identification strategy is refutability (Angrist and Krueger, 1999). Refutability holds that, because identifying assumptions cannot be tested, it is important to think of several alternative ways of measuring the same effect.
} 
regions. The fact that the REBP was targeted to these workers implies that it is difficult to rely on other groups of workers in order to infer the counterfactual.

Moreover, it is possible to test whether previous employment in TR2 (the distinguishing characteristic) leads to different labor market outcomes. The first test relies on data from the pre-program period (Heckman and Hotz, 1989). This test is not very convincing because there exist strong a priori theoretical reasons to expect that an economic downturn affects the two groups differently. For instance, individuals who are resident and employed within a region with labor market problems are expected to suffer stronger from an economic downturn than individuals who are merely resident in that region because they live farther away from the border of that region. However, the main advantage of the this last identification strategy is that the validity of such a counter-argument can be tested. The test involves comparing groups one and two in the pre-reform period (June 1988 until December 1991) when both groups were entitled to the REBP. The difference in the unemployment exit rate during that period is informative about the extent to which the first group was hit by an economic downturn stronger than the second group.

In the post-reform period (January 1992 until August 1993), entitlement to REBP was abolished for individuals belonging to the second group whereas entitlement to REBP continued for the first group. During this period it is possible to identify the causal effect of the REBP on unemployment duration provided that there were no shocks to labor market prospects of the first group that did not occur to the second group to the same extent in the post-reform period. Arguably, this assumption is convincing if the specification test indicates that there were no differences in the transition rate to regular jobs in the pre-reform period. Moreover, in the post-program period (starting August 1993), it is again possible to identify the causal effect of the REBP on unemployment duration because the REBP was abolished for the first group as well.

In sum, this section has put forward four identification strategies with increasing validity in terms of the identifying assumption. The first strategy consists of a DiDiD estimate on the entire dataset. The identifying assumption is strong: the REBP must not have been targeted to the group who was granted eligibility, i.e. policy is assumed to be exogenous. The second strategy recognizes the fact that the REBP was in fact targeted to steel workers. This strategy consists of a DiDiD analysis excluding steel workers. The identifying assumption for this strategy is that there are no substantial indirect effects emanating from the crisis in the steel sector. Because this identification strategy is unlikely to be satisfied if there are general equilibrium effects, we consider a third identification strategy that focuses on a subset of regions, TR1, with a small steel sector and no adverse labor market shocks. The identifying assumption here is that indirect effects emanating from the crisis in the steel sector are comparable to the indirect effects in CR. This is the first identifying strategy which is 'robust' to policy endogeneity bias because it recognizes both, the fact that the policy was targeted to older steel workers 
as well as regions with a dominant steel sector. The final identification strategy is based on the set of TR2 regions. Here, the 1991 REBP-reform created an interesting control group for those individuals who were entitled to the REBP in TR2.

\section{Data and Statistical Model}

To assess the impact of benefit duration on transition rates to new jobs we use longitudinal individual data. These data come from two sources. The first source is the Austrian social security database, which contains detailed information on the individuals' employment, unemployment and earnings history since the year 1972, and some information on the employer like region and industry affiliation. The second source is the Austrian unemployment register from which we use information on the usual socio-economic characteristics. From these data we use the unemployment inflow over the period 1986 to 1995 . The corresponding spells are then followed up to the beginning of 1999.

We restrict our sample to male workers aged 45-54 at the beginning of their spell who held a job prior to unemployment. Selecting a narrow age range has two advantages. First, it is reasonable to assume that (non-eligible) workers aged 45-49 are close substitutes to (eligible) workers aged 50-54 in employment. In this sense, the former are a good control group for the latter. Second, age is a dominant predictor of exit rates from unemployment and the age effect may be highly non-linear. By focusing on this narrow age range we avoid any major bias that may arises from a misspecification of the impact of age on unemployment duration, a problem that may be prevalent in other studies. Obviously, avoiding such a misspecification of the age-effect is crucial in the present analysis because age $\geq 50$ is an eligibility criterion for entitlement to the REBP.

Moreover, we restrict the sample to males. There are two reasons for excluding women. The first reason is access to early retirement. Old age insurance rules allow women to retire already at age 55, whereas the early retirement age for men is $60 .{ }^{14}$ Hence for eligible women the REBP provided a smooth transition to early retirement. The second reason why women were excluded from the analysis is that, one eligibility criterion is a continuous work history (employment in 15 out of the last 25 years). As we can trace back employment histories only until 1972, classification errors are more likely for women than for men.

To avoid such classification errors for the remaining male sample we include only those males with a 'continuous' work history since 1972. A continuous work history is defined as a career with a ratio of actual to potential work experience since the year 1972 of at least 0.7 . This makes sure that only workers who satisfy the work experience requirement with a very high probability are included in the sample. Recall that eligibility requires 780 employment weeks (15 years) within the last 25 years, that

\footnotetext{
${ }^{14}$ Access to early retirement is possible either if the individual has had a long spell of unemployment and/or has paid social security contributions for at least 35 years.
} 
is an actual-to-potential experience ratio of at least 0.6. Since we do not observe the entire 25 yearsperiod prior to the spell, we use the more conservative criterion 0.7 to avoid misclassification. ${ }^{15}$ Between January 1986 and December 1995, in total 953,478 unemployment spells were started by individuals in the age group 45 to 54 . From these, we excluded all 402,401 female spells and those 239,001 spells by males who did not satisfy the work-experience requirement. We ended up with 312,076 spells.

Table 5 shows some information on these unemployment spells: almost two thirds of these spells ended within the first three months, about $85 \%$ were shorter than 6 months, but a substantial fraction (8\%) lasted longer than a year ${ }^{16}$ and more than $4.5 \%$ lasted longer than two years. By far the largest part $(83 \%)$ of the spells ended with a new job, the remaining spells were either exits to long-term sickness $^{17}(5 \%)$ or dropped out of the labor force $(7.7 \%)$. A small number of spells ended with retirement or are censored.

Table 5

The data set contains the usual individual characteristics like education, citizenship status, broad occupation, marital status, industry affiliation, and location of the previous employer; in addition we make use of the more detailed information on the previous employment and unemployment history available in the social security records. Table A2 reports the descriptive statistics and Table A3 reports the definitions of these variables.

Figure 3 shows the monthly Kaplan-Meier hazards for spells eligible to the REBP and for other workers. The group 'other workers' is classified by age in order to allow for a meaningful comparison of the treated spells to other spells. Figure 3 shows that the hazard rate for eligible individuals is considerably lower at all stages of the unemployment spell. This is not surprising when comparing the treated hazard to the hazard rate of the non-eligible spells of individuals aged 45 to 49 because such a difference may also be due to the lower age in the comparison group. However, when comparing the treated spells with the non-eligible individuals who are aged 50 to 54, the age effect is held constant. Nevertheless, it appears that the transition rate to regular jobs was much lower for individuals entitled to the REBP than for those who were not eligible. Thus, this rough descriptive comparison of the Kaplan-Meier hazard rates shows that the REBP affected the transition rate to regular jobs negatively.

\footnotetext{
${ }^{15}$ We also excluded those among the remaing individuals who were employed less than 156 weeks within the last 5 years, less than 312 weeks within the last 10 years, and less than 468 weeks within the last 15 years. This guarantees that all individuals in our sample are eligible for at least 30, 39, and 52 weeks of UBs.

${ }^{16}$ Note that these numbers are drawn from an inflow rather than a stock sample (to which offical numbers on the percentage long-term unemployment usually refer). Clearly, the fraction of long-term unemployed as a fraction of the unemployment stock at an arbitrary point of time is larger than $10 \%$ due to the well-known oversampling of long-term spells in stock-samples.

${ }^{17}$ In accordance with the literature, long-term sickness is defined as a sickness spell that lasts longer than 3 months. Unemployment spells that are interrupted by short-term sickness spells are lumped together. This is in line with UBeligibility rules. During sickness the claim is interrupted, and can be used up after the sickness spell ends.
} 
Of course, such differences may also be due to the fact that the REBP was enacted in regions with labor market problems. Section 5 addresses this issue in detail.

Figure 3

The Statistical Model Suppose that the escape rate from unemployment, denoted by $\theta$, is given by

$$
\begin{aligned}
\theta\left(\tau ; A, \Delta_{1}, \Delta_{2}, T R ; x\right)= & \lambda(\tau) \exp \left(\alpha x+\beta_{0} \Delta_{1}+\beta_{1} \Delta_{2}+\beta_{2} T R+\beta_{3} A\right. \\
& +\gamma_{1} \Delta_{1} T R+\gamma_{2} \Delta_{1} A+\gamma_{3} \Delta_{2} T R+\gamma_{4} \Delta_{2} A \\
& \left.+\delta_{1} \Delta_{1} T R \cdot A+\delta_{2} \Delta_{2} T R \cdot A\right)
\end{aligned}
$$

where $\tau$ is the elapsed duration of unemployment, $\Delta_{1}$ is an indicator taking the value 1 as of the date when the REBP started, $\Delta_{2}$ is the corresponding indicator as of the date when this law was abolished; $T R$ is a dummy variable that indicates whether or not an individual lives in a treated region; $A$ is an age dummy that indicates whether or not an individual is 50 years or older; $x$ is a vector of additional control variables and $\alpha$ is the corresponding vector of coefficients; and finally $\lambda$ is the baseline hazard.

The $\beta$-coefficients control, respectively, for differences in unemployment escape rates due to changes in job prospects over time $\left(\beta_{0}\right.$ and $\left.\beta_{1}\right)$, permanent differences across regions $\left(\beta_{2}\right)$ and permanent differences between workers under 50 and those 50 and above $\left(\beta_{3}\right)$. The $\gamma$-coefficients capture timeseries changes in job-chances between regions and between age-groups, respectively, as of the date when the REBP starts $\left(\gamma_{1}\right.$ and $\left.\gamma_{2}\right)$ and as of the date when the law was abolished $\left(\gamma_{3}\right.$ and $\left.\gamma_{4}\right)$.

The interesting coefficients are the two $\delta$-coefficients: these coefficients capture all variation in unemployment durations specific to the older individuals (relative to the younger) in the treated regions (relative to control-regions) in the years when the law was in effect (relative to before the law; $\delta_{1}$ ) and in the years after which the law was abolished (relative to during the law; $\delta_{2}$ ). These coefficients are the DiDiD-estimates of, respectively, introducing and abolishing the REBP. Clearly, if the policy effects are symmetric we have $\delta_{1}=-\delta_{2}$. Hence, we can test for persistence-effects of the REBP which occur if $\delta_{1}>-\delta_{2}$, when the hazard rate in the treated regions does not return to its pre-introduction level.

The escape rate from unemployment to a regular job is assumed to be multiplicatively separable in elapsed duration $\tau$ and covariates. This means that we can estimate the model by partial likelihood, as proposed originally by Cox (1972). The advantage of this approach is that duration dependence of the baseline hazard $\lambda(\tau)$ can be left unspecified in the Cox-proportional hazard model. This is important because parameter estimates tend to be biased if the duration dependence pattern is misspecified. In all estimates, inference is based on robust standard errors that take into account the possibility that observations may not be independent within labor market regions. ${ }^{18}$

\footnotetext{
${ }^{18}$ This problem is discussed in the regression context by Moulton (1990). Lin and Wei (1989) develop the robust estimator for the Cox Proportional Hazard model that is applied in the present context. Note that allowing for possible
} 


\section{Results}

As outlined in Section 3 the empirical strategy is to estimate the causal effect of the extended benefits granted by the REBP in four steps. We start with a simple differences-in-differences-in differences estimator that makes use of the fact that eligibility depends on age, region of residence and/or previous employer, and calendar time. In a second step we redo this analysis for a sample that excludes steel workers because elderly individuals entering unemployment from that sector were the primarily targeted group of the program. In a third step, we compare individuals from a subset of regions that were excluded from treatment after the REBP reform. These regions have a steel sector similar in size to control regions; and these regions had also labor market conditions similar to control regions. The final step makes use of the tightening of eligibility criteria that came with the REBP-reform in 1991. Focusing on individuals aged 50 or older, it compares the duration of unemployment spells by individuals who were both resident and employed in a REBP-region to individuals who were resident in a REBP-region but employed in a control region. The former group was entitled to extended benefits throughout the period 1988 - 1993, whereas spells of the latter group that started after the REBP-reform in 1992 were not entitled.

These four strategies differ in terms of the assumption required to identify the causal effect of benefit entitlement on unemployment duration. A comparison of the results across strategies serves to infer the validity of the respective identifying assumption.

Strategy I: The DiDiD estimator The DiDiD estimator infers the causal impact of the duration of benefit entitlement on the duration of unemployment from data on unemployment duration by age, region, and time. Region-specific shocks (independent of age) and age-specific shock (independent of location) are controlled for. The central idea is that effects that are specific to both age and region are entirely due to benefit eligibility status. If this latter assumption is satisfied, the DiDiD-procedure yields an unbiased estimate for the causal impact of the REBP on the duration of unemployment.

To get a first impression on the impact of the REBP we perform a simple DiDiD calculation (Table 6 ). The first row shows the fraction of spells that end in long-term unemployment (lasted longer than 12 months) for the 'treated' - those individuals aged 50-54 at the beginning of their spell, living in a REBP-region. Before the law was introduced, $6 \%$ of all spells ended in long-term unemployment, during the treatment period this fraction increased to almost $30 \%$, and after the law was abolished it decreased again to $15 \%$. This is quite different from the respective figures for the control group within the region - those aged 45-49 at the beginning of their spell, living in a REBP-region. Here deviations from independence within labor market regions also addresses the concern with serial correlation in DiDiD analyses (Bertrand et al., 2002). We correct for clustering within the labor market regions of the Austrian unemployment insurance administration (AMS). There are roughly 100 of these regions. 
the fraction amounted to about $4 \%$ before and during treatment, and increased slightly above $5 \%$ after abolishment. The corresponding comparison for non-REBP residents, older than age 50, yields a continuous increase of the fraction long-term unemployed from $4 \%$ before, to $8 \%$ during, to $12 \%$ after the treatment period. In sum, according to the DiDiD-estimate, the risk of long-term unemployment increased by 21.4 percentage points between the period before introduction and the treatment period. And it decreased by 18.5 percentage points between the treatment period and the period after the law was abolished.

Table 6

Tables 7 applies the Cox-proportional hazard model for transitions to a new job (Column 'Strategy I'). In the estimates, we control for marital status, education, skill level, nationality, type of job, recall status, previous industry, quarter of inflow, unemployment history, work experience, and the regional unemployment rate in the age bracket 45 to 54. This last variable is measured at the beginning of the second quarter of each year and is time-varying. This variable is a measure for competition for jobs. Table A1 reports results on the effect of all these covariates.

The results indicate that the effect of introducing the REBP is very large. ${ }^{19}$ The $\log$ hazard rate decreases by .477 which means that the transition rate from unemployment to a regular job for the treated individuals with 209 week of benefit duration is about $37.9 \%(1-\exp (-.477)=.379)$ lower than in the counterfactual state of a potential benefit duration of 30 weeks.

Table 7

Does abolishing the benefit program lead to a reversal of this picture? Table 6 shows that it does, but it also shows that there is an asymmetry between the effect of the introduction and the effect of the abolishment of the REBP. The log hazard rate increases by .390 after abolishment of the law which is quantitatively large but significantly lower in size than the effect of introduction.

There are basically two possible reasons for this asymmetry. First, a long-term program such as the REBP causes a persistent change in behavior and escape rates may not return to pre-program levels after the law has been abolished. The second possible reason is that the estimated effects do not only measure effects caused by extended benefits, but also group specific differences in labor market shocks. In the latter case, the estimated asymmetry is due to larger differences in the labor market conditions before and during the program, as compared to the differences during and after the program.

Clearly, the conclusion that the REBP has caused strong effects on escape rates from unemployment to a regular job and that there are asymmetric effects between the introduction and the abolishment of the program depends on the validity of our identifying assumption. The DiDiD estimator relies upon a strong assumption: namely that there are no shocks idiosyncratic to the group of treated individuals.

\footnotetext{
${ }^{19}$ See Table 9 for simulations showing the effect on expected duration.
} 
Strategy II: Excluding steel workers The identifying assumption is unlikely to be satisfied. The REBP was targeted towards older workers, living in regions with a dominant nationalized (steel) sector (Hesoun, 1988). In 1988, almost $18 \%$ of private sector employment was concentrated in the steel sector in treated regions. The corresponding figure was $4.8 \%$ for the control regions.

The second identification strategy consists of a DiDiD analysis excluding steel workers. If steel workers suffered from specific shocks this identification strategy is expected to deliver different results from the first one (DiDiD on the entire sample). If such adverse shocks to labor market prospects were concentrated in the steel sector, leaving other sectors unaffected, excluding steel workers is a valid strategy to eliminate the policy endogeneity bias.

Table 7 present the results from this analysis (Column 'Strategy II'). The number of spells used for this analysis is 280,871 because data on 31,205 individual spells with previous employment in the steel industry has been omitted. ${ }^{20}$ The treatment effects, both the effect of introduction and the effect of abolishment are considerably lower in absolute value. The quantitative impact of the REBPintroduction reduces by more than a third (in absolute value), from -.477 to -.294. Similarly, the estimated effect of the abolishment of the program leads decreases from .390 to .255. However, the effect of introducing the REBP is estimated to be stronger than the effect of abolishing the REBP, i.e. the asymmetry is still apparent.

\section{Strategy III: Treated regions with favorable labor market conditions and a small steel} sector Table 7 presents the results from the first 'robust' identification strategy (Column 'Strategy III'). Recall that the idea is to identify the causal effect of the REBP by relying on treated individuals within the set of TR1 regions. As Section 3 shows, these regions are characterized by a steel sector of identical size to the rest of Austria. Moreover, there were no adverse labor demand shocks within TR1 regions during the period when the REBP was in effect.

The estimated REBP coefficients are substantially smaller in absolute value. ${ }^{21}$ The quantitative impact of the benefit extension is highly significant, but quantitatively not particularly strong. Introducing or removing the REBP-status changes the log-hazard rate by .185. Compared to the results of the second identification strategy, the effect of introduction reduces more strongly than the effect of abolishment of the REBP. Interestingly, the effects of introduction and abolishment are now symmetric.

A potential explanation is that negative spillover effects that were transmitted by the steel crises were strongest when this crises was at its peak. The peak occurred when the REBP was in effect, hence the introduction effect is large. A procedure that removes those indirect effects should estimate a

\footnotetext{
${ }^{20}$ An alternative, albeit more restrictive, approach to assessing the stability of the REBP-effect would be to add a complete set of interactions for job seekers that were previously employed in the steel sector. Results based on that procedure are very similar to those in Table 7 .

${ }^{21}$ The number of spells used in this analysis is 233,223 consisting of all non-steel, non-TR2 residence spells. Thus, information on 47,648 unemployment spells of non-steel workers with residence in TR2 is discarded.
} 
considerably lower introduction effect. Indirect effects are of lower importance at the end of the REBP period and differences in labor market conditions have become less pronounced. Hence an estimate that is not afflicted with these indirect effects should not be very much smaller than an estimate that does not account for these indirect effects.

While this third identification strategy is robust, the eligibility status was not randomly assigned. Identification is based on a non-testable assumption. This motivates the application of a further, similarly 'robust' strategy that is based on an entirely different assumption and on an entirely different data set.

Strategy IV: Employment and residence as eligibility criteria The 1991 reform tightened eligibility criteria within TR2s. Before 1992, the entitlement criterion referring to the location of the unemployed individual was solely that the individual had to be resident in a treated region. As of 1992, entitlement to the REBP was confined to individuals with residence and previous employment within a TR2. We use this change in eligibility criteria to design our final identification strategy. We focus on two groups of individuals: the first group was previously resident and employed in TR2; and the second group was resident in TR2 but not previously employed in TR2. (Throughout this subsection we concentrate on workers above age 50.) These two groups are interesting because they had the same treatment status during the first REBP-period (before the reform, June 1988 until December 1991). After the reform, however, only the first but not the second group was eligible to the REBP. The causal effect of the benefit extension on the duration of unemployment can be identified provided that there were no shocks during the post-reform period that affected one group differently than the other group.

Table 8 summarizes our empirical design and performs a simple DiD calculation focussing on the incidence of long-term unemployment (spells lasting longer than 12 months). The analysis is based on 22,091 spells by workers aged 50 years or older which were resident in one of the TR2 regions at the beginning of the unemployment episode. Note first that the group of TR2 residents that was previously employed in a region not covered by the REBP is sufficiently large, so meaningful statistical inferences can be drawn. ${ }^{22}$ Second, Table 8 shows that eligibility status of the two groups differs only in the third out of the four sub-periods shown in the table. In the pre-program period, the percentage of spells ending up in long-term unemployment is $5.3 \%$ for the first group, and slightly larger for the second group (6.7 \%) (Column 'Before policy'). In the pre-reform period, both groups were entitled to the program. Note that the risk of long-term unemployment increases almost by the same amount for both groups as indicated by the 'Employment difference' of - $0.5 \%$ (Column 'During policy (I)'). Note further that the DiD comparison between the pre-program period and the pre-reform period suggest no significant differences between the two groups. This is support for the identifying assumption which holds that the two groups face similar labor market conditions in the post-reform (January 1992 until

\footnotetext{
${ }^{22}$ The number of observations in this group exceeds 1300 in all four periods considered.
} 
August 1993) and in the post-program period (starting August 1993).

In the post-reform period, there is a further increase in the risk of long-term unemployment for the first group (by about $8 \%$ ) but a substantially smaller increase for the second group (less than 3 \%) (Column 'During policy (II)'). The DiD estimate reveals that the increase in the risk of long-term unemployment is stronger by 4.8 percentage points in the first group. This effect, arguably, can be attributed to the fact that the REBP was abolished for the second group but remained in effect for the first group. In the post-program period, the DiD estimate for the second abolishment effect (After During II) amounts to 6.6 \% (Column 'After policy'). Both abolishment effects are significantly different from zero, but not significantly different from each other.

Table 8

The results presented in Table 7 refer to the same DiD analysis additionally controlling for observed characteristics (Column 'Strategy IV'). The results are almost identical to the one obtained from our third identification strategy. For the second group (just resident in TR2) covered in our sample, abolishment of the REBP leads to an increase in the log hazard rate of $.186 .{ }^{23}$ There is a corresponding decrease in the hazard rate when the REBP was also abolished for the first group (the effect on the log hazard being .185).

An additional advantage of our fourth identification procedure is that one can test whether the second group is an appropriate comparison group to the first one. In the pre-reform period both groups had the same eligibility status and any differences in the exit behavior between them should be entirely due to labor market conditions. The results in Table 7 suggest that, in fact, there were no significant differences in escape rates between the two groups in the pre-reform period (coefficient 'Change in Employment effect'). ${ }^{24}$ This is good news for the second 'robust' identification strategy: The idea is that, if the labor market conditions are identical in the pre-reform period, they should not be significantly different in the second post-reform period. This means that our estimates in fact represent a causal effect of the REBP on the transition rate from unemployment to a new job in the periods when we can not observe the difference in labor market chances for the two groups. ${ }^{25}$

\footnotetext{
${ }^{23}$ The parameter estimate shows the change in the hazard rate for the first group compared to the second group. The abolishment effect is thus -1 times this parameter estimate.

${ }^{24}$ Note that it is also possible to perform this test before the program was implemented. The value of such comparisons is clearly lower than the value of being able to compare the treated and the control group while the policy was in place. Nevertheless, this comparison, again, shows that there are no significant differences in the transition rate to jobs before the program (see Table A1, coefficient 'Resident and employed' testing for differences between group one and group two before the program was enacted).

${ }^{25}$ Note that allowing for the fact that the unemployment exit rate tends to increase strongly when unemployment benefits are exhausted (Meyer, 1990) does not alter the results reported in Table 7 . When we allow for changes in the hazard rate as a function of time until benefit exhaustion, the estimated REBP effects are -.178 ("REBP introduced"; Strategy III), .176 ("REBP abolished; Strategy III), -.179 ("REBP abolished, employed and resident"; Strategy IV), .179
} 
Discussion of Benefit Entitlement Results The fact that the previous two 'robust' identification strategies produce identical results is remarkable because these two procedures are quite different. First, Strategy III relies on the identifying assumption that eligible workers in TR1s face similar labor market conditions as non-eligible workers in CRs. In contrast, the present Strategy IV assumes that there are no idiosyncratic shocks to labor market prospects with respect to employment in TR2 for those who live in TR2. Moreover, the results are based on entirely different data in the last as compared to the previous strategy. No spell that is used in the previous procedure is used in the final procedure.

On the other hand, note that the Strategy IV, like Strategy III, is 'robust' in the sense that the estimated effect of benefit duration is unlikely to be contaminated by direct or indirect effects transmitted by the steel crises. Also here we exclude steel workers from our sample; and as both groups were located in the same set of regions (here we rely entirely on TR2 residents) indirect effects that affect one group but not the other are not likely.

Thus, a comparison of the results of these two 'robust' identifying strategies is likely to be meaningful in the sense that it is possible to infer the validity of the identifying assumptions. Would both approaches deliver different results it appears that at least one identifying assumption has been violated. If results based on the two different strategies are very similar, however, it is more likely that both identifying assumptions are valid. The alternative would be the knife-edge case where the group-specific shocks in TR1s and CRs are exactly identical to the idiosyncratic shocks within TR2. This seems to be the less likely scenario.

Thus, based on the fact that Strategy III and Strategy IV deliver identical results, it appears to be the case that both 'robust' strategies identify the causal effect of the REBP on unemployment duration. Confidence in the estimated effect is further supported by the fact that the estimated effects are similar when introducing the program as when abolishing the program (Strategy III), and that abolishing the program has the same effect for two different groups of workers (Strategy IV). Such a result is not likely to arise if the identifying assumptions are violated.

Socio-economic and other characteristics All results presented in the Table 7 are based on hazard rate models that include a large number of covariates (Table A1 reports full results for all four identification strategies). Here we mention the importance of the various determinants only briefly. Married males have higher escape rates from unemployment than unmarried workers. A medium level of education (apprenticeship) decreases the escape rate slightly (relative to low education), but the exit ("REBP abolished, resident"; Strategy IV). All REBP effects are significantly different from zero (5\% level). The "change in employment effect" is not significantly different from zero; this indicates that there were no differences in the transition rate to regular jobs with respect to previous employment in TR2. The main reason for this minor change in results is that benefit exhaustion effects are not quantitatively important. 
rate of highly educated workers is well below the one of the lower educated. ${ }^{26}$ Blue collar workers have much higher transition rates to job than white collar workers and immigrants have a higher transition rate than natives. Previous industry turns out very important. On the one side, seasonal industries (tourism and construction) have shorter unemployment spells which is in part the result of recalls by previous employers. On the other side, workers from the steel industry face job chances significantly lower than in other industries (based on column 'Strategy I'). Moreover, the previous unemployment and employment history is an important determinant of the duration of unemployment spells. Unemployment in the past is associated with a higher escape rate, but the cumulative duration of past unemployment decreases the chance to get a job. A continuous working career in the past decreases the exit rate from unemployment. Finally, the regional labor market conditions are of high importance. This variable is approximated by the regional unemployment rate of males aged 45-54 measured at the beginning of the second quarter of each year. ${ }^{27}$ Hence, this variable is a measure for competition for jobs and a predetermined variable. The higher the regional unemployment rate the lower is the individual unemployment exit rate.

Simulations We can use the results from the various procedures to simulate the impact of the REBP on the duration of unemployment of a typical worker (Table 9). ${ }^{28}$ Expected unemployment duration for this worker is almost 19 weeks. How much does the REBP affect this expected duration? According to our first identification strategy (simple DiDiD), the benefit extension will lead to a threefold increase in the expected unemployment duration which amounts to almost 53 weeks. The results imply an increase of .189 weeks of unemployment per additional week of extended benefits. The corresponding simulation from our second identification strategy yields less dramatic results, but also predicts a doubling of the duration of unemployment and an increase in .098 weeks per additional week of unemployment. Finally, our 'robust' identification strategies predict that the REBP increases unemployment duration by $50 \%$ and this increase amounts to .055 per additional week of extended benefits.

How do these estimates from the robust identification strategies compare to other studies? Our result

\footnotetext{
${ }^{26}$ One reason for this result may be that the higher educated individuals are more specialised and thus the job offer rate may be lower for individuals with higher as opposed to lower education.

${ }^{27}$ This covariate is predetermined and varies each year. This means that the information on the regional unemployment rate is updated for all spells that are in progress at that time. This information is predetermined because we only use historical information in explaining the transition rate in the year that follows.

${ }^{28}$ The reference individual is married, has low education, is a blue collar worker, Austrian, looking for part-time or unknown type of job, not on recall, became unemployed in the first quarter, from other industry, was unemployed at least once, and has average values of the continuous covariates (unemployment duration in the past, work experience, and regional unemployment rate). Expected duration of unemployment until a regular job starts is $E(T \mid x)=\lim _{U \rightarrow \infty} \int_{0}^{U} \exp \left(-\int_{0}^{t} \widehat{\theta}(z) d z\right) d t$ where $\widehat{\theta}(z)$ is the estimated transition rate to jobs for the reference worker (Lancaster, 1990). $U$ was chosen such that simulated expected duration converges. Note that there is a highly non-linear relationship between the transition rate to jobs and expected duration.
} 
is well below the range of the estimates found in studies concerning the U.S. system. For instance, Katz and Meyer (1990) identify an increase of .16 to .20 weeks per additional week of benefit entitlement. The first reason for the fact that the estimates identified in the present study are substantially smaller could be that Katz and Meyer (1990) do not account for the endogeneity of extended benefits, which for the case of Austria turns out very important. Indeed, the study by Card and Levine (2000) that accounts for policy endogeneity finds a substantially smaller effect per week of about .08. ${ }^{29}$ Thus, policy endogeneity is an important problem also in U.S. studies. A second reason is that the end of entitlement to regular unemployment benefits entails a smaller drop in income in the case of Austria compared to the U.S. Individuals whose benefits have run out may rely on "transfer payments for those in need" ('Notstandshilfe') if they pass the means-test. ${ }^{30}$ A final reason for the comparably low REBP-impact may simply come from the fact that the benefits extension was so large. An increase in benefit entitlement from 26 to 39 weeks (the U.S. case) will have a stronger impact than the same 13 weeks-extension if it extends benefits from 196 to 209 weeks.

Table 9

Table 9 suggests that it is possible to decompose policy endogeneity into severe labor market problems for steel workers ('idiosyncratic steel shock') and in spillovers affecting the entire region ('steel spillover'). The change in the estimated REBP-effect when going from Strategy I to Strategy II is about 16.3 weeks (=33.8-17.5). Recall, that Strategy II differs from Strategy I merely due to the exclusion of steel workers. Hence, the difference in the 'REBP-effect' between these two strategies is an estimate of the 'idiosyncratic steel shock' affecting older workers in the steel sector during the period when the REBP was in effect. The 'idiosyncratic steel shock' seems to have increased unemployment duration by about 16 weeks. This is a substantial effect compared to the causal effect of the REBP. The size of the 'steel spillover' effect can be gauged by comparing Strategy III with Strategy II: The reduction in the implied effect of the REBP is about 7.7 weeks (=17.5-9.8). Recall that Strategy III concentrates on individuals residing in TR1, a set of regions with a steel sector that is comparable in size to the rest of Austria. Thus, the negative spillovers emanating from the steel sector may have prolonged individual unemployment duration by almost 8 weeks. This general equilibrium effect is substantially smaller than the idiosyncratic steel shock, and comparable in magnitude to the REBP-effect.

\footnotetext{
${ }^{29}$ Note that the change in the per week effect of benefit entitlement due to policy endogeneity is almost the same as that reported in Table 9.

${ }^{30}$ Note that also in the U.S. some groups among the unemployed could also rely on rather generous welfare provisions. For instance, income from unemployment insurance and income from welfare programs is quite similar for households with two children. The situation has changed due to the 1996 Welfare Reform Act that has introduced strong work requirements making it harder for unemployed individuals to draw cash benefits (Moffit, 2002).
} 


\section{Conclusions}

In June 1988 the Austrian government enacted, in 1991 reformed, and in August 1993 abolished, the Regional Extended Benefits Program (REBP). This program extended entitlement to regular unemployment benefits from 30 weeks to a maximum of 209 weeks for elderly individuals in certain regions. In this paper, we exploit the successive changes in unemployment insurance rules provided by the REBP and use a large and informative data set to evaluate the impact of the program on the incentives to take up a regular job.

A central problem of previous studies is that the reasons for changes in benefit rules are typically not accounted for. However, when benefit policy is endogenously determined by labor market conditions, observed changes in unemployment duration are partly due to a worse job market conditions and the estimates of the impact of benefit generosity on unemployment durations will be biased. The Austrian REBP offers the unique possibility to discuss the empirical relevance of policy endogeneity in the econometric evaluation of policy measures. Moreover, the Austrian REBP offers the unique opportunity to investigate how a policy change as large as the maximum U.S.-European differential in benefit eligibility duration might affect the duration of unemployment holding everything else constant.

We address the endogenous policy issue by applying two 'robust' identification strategies. First, we exploit the fact that a subset of entitled regions faced employment conditions very similar to regions that were not covered by the REBP. Second, the 1991-reform of this program changed eligibility criteria such that claimants had to be not only resident but also previously employed in a treated region. This policy reform created variation in the REBP-status for workers of identical age living in the same region. Such variation is useful in discussing identification of the causal effect of benefit entitlement on unemployment duration. Both of these strategies allow a comparison between individuals that had rather similar labor market conditions but a different eligibility status. These two completely different identification strategies yield almost identical results. This can be taken as evidence that these strategies succeed in addressing policy endogeneity.

The main results are: (i) The increase in UB-entitlement from 30 to 209 weeks reduces the transition rate to jobs by $17 \%$. The program increased expected unemployment duration by about 9 weeks, leading to an increase in unemployment duration per week of additional benefits of 0.055 . (ii) The effect of introducing and the effect of abolishing the program are of the same magnitude. Hence, the behavior of individuals is symmetric with respect to the direction of the benefit change. (iii) Accounting for policy endogeneity is important. Estimates which fail to do so suggest that the transition rate to regular jobs reduces by $40 \%$ (instead of $17 \%$ ) due to REBP. 


\section{References}

[1] Abbring, J, Van den Berg G and J van Ours (1998), The Effect of Unemployment Insurance Sanctions on the Transition Rate from Unemployment to Employment, Working Paper, Tinbergen Institute, Amsterdam.

[2] Angrist, J D and A B Krueger (1999), Empirical Strategies in Labor Economics, in Ashenfelter, O and D Card (eds.), Handbook of Labor Economics, Elsevier.

[3] Atkinson, A and J Micklewright (1991), Unemployment Compensation and Labor Market Transitions: A Critical Review, Journal of Economic Literature 29, 1697-1727.

[4] Marianne Bertrand, Duflo, E and S Mullainathan (2002), How Much Should We Trust Differencesin-Differences Estimates?, NBER Working Paper No. 8841, Massachusetts: NBER.

[5] Besley, T and A Case (1994), Unnatural Experiments? Estimating the Incidence of Endogenous Policies, NBER Working Paper No. 4956, Cambridge Mass.

[6] Bover, O, Arellano, M and S Bentolila (1998), Unemployment Duration, Benefit Duration and the Business Cycle, CEPR Working Paper No. 1840, London.

[7] Bratberg, E and K Vaage (2000), Spell Durations with Long Unemployment Insurance Periods, Labour Economics 7: 153-80.

[8] Burdett, K (1979), Unemployment Insurance as a Search Subsidy: A Theoretical Analysis, Economic Inquiry 17, 333-343.

[9] Card, D E (1990), The impact of the Mariel boatlift on the Miami labor market, Industrial and Labor Relations Review, 43, 245-257.

[10] Card, D E and P B Levine (2000), Extended Benefits and the Duration of UI Spells: Evidence from the New Jersey Extended Benefit Program, Journal of Public Economics 78: 107-138.

[11] Carling, K, Edin, P-A, Harkman A and B Holmlund (1996), Unemployment Duration, Unemployment Benefits, and Labor Market Programs in Sweden, Journal of Public Economics 59, 313-334.

[12] Carling, K, Holmlund, B and A Vejsiu (2001), Do Benefit Cuts Boost Job Findings? Swedish Evidence from the 1990s, Economic Journal, 766-790.

[13] Cox, D R (1972), Regression Models and Life-Tables (with discussion), Journal of the Royal Statistical Society, Series B 34: 187-220.

[14] Ham, J and S Rea (1987), Unemployment Insurance and Male Unemployment Duration in Canada, Journal of Labor Economics 5: 325-53. 
[15] Heckman, J J and Hotz, J (1989), Choosing Among Alternative Nonexperimental Methods for Estimating the Impact of Social Programs: The Case of Manpower Training, Journal of the American Statistical Association, 84 (408), 862-880.

[16] Hesoun, J (1988), Bericht des Ausschusses für soziale Verwaltung, Beilage zu den Stenographischen Protokollen Des Nationalrates 549, Vienna.

[17] Hunt, J (1995), The Effect of Unemployment Compensation on Unemployment Duration in Germany, Journal of Labor Economics 13, 88-120.

[18] Katz, L and B Meyer (1990), The Impact of the Potential Duration of Unemployment Benefits on the Duration of Unemployment, Journal of Public Economics 41, 45-72.

[19] Lalive, R, Van Ours, J C and J Zweimüller (2000), The Impact of Active Labor Market Programs and Benefit Entitlement Rules on the Duration of Unemployment, CEPR Working Paper No. 2451, London.

[20] Lalive, R and J Zweimüller (2002), Benefit Entitlement and the Labor Market: Evidence from a Large-Scale Policy Change, IEW Working Paper No. 105, University of Zürich.

[21] Lancaster, T (1990), The Econometric Analysis of Transition Data, Cambridge: Cambridge University Press.

[22] Lin, D Y and Wei, L J (1989), The Robust Inference for the Cox Proportional Hazards Model, Journal of the American Statistical Association, 84(408): 1074-1078.

[23] Meyer, B (1990), Unemployment Insurance and Unemployment Spells, Econometrica 58, 757-782.

[24] Meyer, B (1995a), Natural and Quasi-Experiments in Economics, Journal of Business and Economic Statistics, 13(2), 151-161.

[25] Meyer, B (1995b), Lessons from the U.S. Unemployment Insurance Experiments, Journal of Economic Literature, 33(1), 91-131.

[26] Moffit, R and W Nicholson (1982), The Effect of Unemployment Insurance on Unemployment: The Case of Federal Supplemental Benefits, Review of Economics and Statistics 64: 1-11.

[27] Moffit, R (1985), Unemployment Insurance and the Distribution of Unemployment Spells, Journal of Econometrics 28: 85-101.

[28] Moffit, R (2002), The Temporary Assistance for Needy Families Program, NBER Working Paper No. 8749, Massachusetts: NBER. 
[29] Mortensen, D (1977), Unemployment Insurance and Job Search Decisions, Industrial and Labor Relations Review 30, 505-517.

[30] Moulton, B R (1990), An Illustration of a Pitfall in Estimating the Effects of Aggregate Variables on Micro Units, Review of Economics and Statistics 72(2): 334-338.

[31] Nickell, S and R Layard (1999), Labor Market Institutions and Economic Performance, in Ashenfelter, O and D Card (eds.), Handbook of Labor Economics, vol 3C. Amsterdam: North-Holland.

[32] OECD (1995), OECD Employment Outlook, Paris.

[33] OECD (1996), OECD Employment Outlook, Paris.

[34] Van den Berg, G (1990), Nonstationarity in Job Search Theory, Review of Economic Studies 57, 255-277.

[35] Van den Berg G, Van der Klaauw, B and J van Ours (2002), Punishing Welfare Recipients for Noncompliance with Job Search Guidelines, Journal of Labor Economics, forthcoming.

[36] Winter-Ebmer, R (1998a), Potential Unemployment Benefit Duration and Spell Length: Lessons from a Quasi-Experiment in Austria, Oxford Bulletin of Economics and Statistics 60: 33-45.

[37] Winter-Ebmer, R (2002), Benefit Duration and Unemployment Entry: Quasi-Experimental Evidence for Austria, European Economic Review, forthcoming. 
Table 1: Unemployment rate and long-term unemployment in treated and control regions in the year before REBP was enacted

\begin{tabular}{ccc}
\hline \hline & $\begin{array}{c}\text { Unemployment } \\
\text { rate }\end{array}$ & \\
\cline { 2 - 3 } A. Treated regions & & $\begin{array}{c}\text { Percentage of } \\
\text { long-term unemployed }\end{array}$ \\
\cline { 2 - 3 } age 45-49 & 3.6 & \\
age 50-59 & 4.0 & 15.7 \\
B. Control regions & & 22.3 \\
age 45-49 & 4.0 & 17.4 \\
age 50-59 & 4.9 & 23.4 \\
\hline \hline
\end{tabular}

Notes: $\quad$ Treated region $=$ region with entitlement to REBP. Long-term unemployment $=$ spell lasts longer than 12 months.

Source: Own calculations, based on Austrian Social Security data. 
Table 2: Unemployment spell characteristics:

Steel workers vs non-steel workers

\begin{tabular}{|c|c|c|c|}
\hline & All spells & Treated spells & Non-treated spells \\
\hline \multicolumn{4}{|c|}{ Mean completed duration (days) } \\
\hline Steel workers & 219.92 & 490.14 & 146.05 \\
\hline Non-steel workers & 110.32 & 200.39 & 105.58 \\
\hline \multicolumn{4}{|c|}{ Exit to employment (share of total) } \\
\hline Steel workers & .657 & .350 & .753 \\
\hline Non-steel workers & .851 & .740 & .857 \\
\hline \multicolumn{4}{|l|}{ Observations } \\
\hline Steel workers & 31205 & 7431 & 23774 \\
\hline Non-steel workers & 280871 & 14479 & 266392 \\
\hline
\end{tabular}

Notes: Steel workers: individuals formerly employed in the steel industry.

Source: Own calculations, based on Austrian Social Security data. 
Table 3: Aggregate statistics, by type of treated region

\begin{tabular}{|c|c|c|c|}
\hline & TR1 & TR2 & $\mathrm{CR}$ \\
\hline Entitled to REBP & $\begin{array}{l}\text { In pre-reform } \\
\text { period }\end{array}$ & $\begin{array}{l}\text { In pre- and post- } \\
\text { reform period }\end{array}$ & Never \\
\hline Percentage employment in steel industry ${ }^{\text {a) }}$ & 8.9 & 19.2 & 4.8 \\
\hline \multicolumn{4}{|l|}{ Percentage votes for ${ }^{\mathrm{b})}$} \\
\hline Social democrats (SPÖ) & 38.5 & 47.8 & 41.1 \\
\hline Conservatives (ÖVP) & 49.6 & 38.4 & 43.3 \\
\hline \multicolumn{4}{|l|}{ Head of ÖVP } \\
\hline In pre-program period & from TR1 & & \\
\hline In pre-reform period & & from TR2 & \\
\hline In post-reform period & & & from $\mathrm{CR}$ \\
\hline
\end{tabular}

Notes: $\quad$ Pre-program period ends in May 1988; pre-reform period: June 1988 until December 1991; post-reform period: January 1992 until July 1993; post-program period starts August 1993.

a) The year before REBP was enacted, average.

b) In 1986 elections for the parliament.

Source: Own calculations, based on Austrian Social Security data; Statistics Austria. 
Table 4: Labor market conditions in treated regions and control regions 1981-1998 Regression results

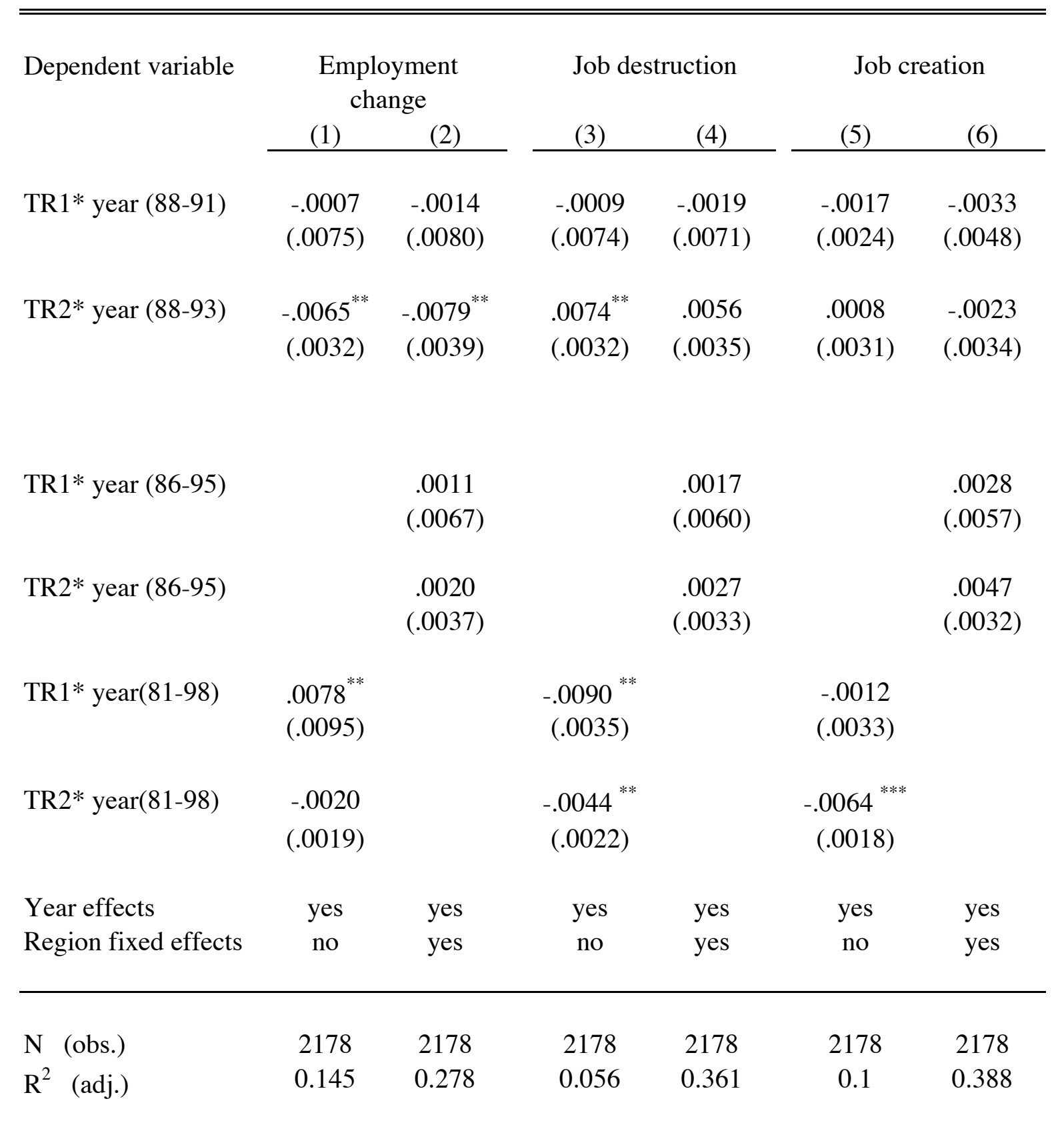

Notes: $\quad$ See previous table for definition of TR1, TR2, CR. One observation per year for 121 regions.

Source: Own calculations, based on Austrian Social Security data. 
[N] [ Fraction ]

Durations

$>=3$ months

$113252 \quad .363$

$>=6$ months

.151

$>=9$ months

.103

$>=12$ months

.080

$>=24$ months

25091

.046

Mean completed duration (days)

120.808

Exit status

employment
retirement
long-term sickness
out of labor force
right censored

259533

.832

$6815 \quad .022$

$16015 \quad .051$

$23918 \quad .077$

$5795 \quad .019$

Total

312076

1.000

Notes: $\quad$ Mean completed duration = mean duration of unemployment for non-right-censored spells. Long-term sickness $=$ sickness spell lasting longer than 3 months.

Source: Own calculations, based on Austrian Social Security data. 
Table 6: The effect of REBP on the risk of long-term unemployment DiDiD - estimate

\begin{tabular}{lcccc}
\hline \hline & & & & \\
Location / year & $\begin{array}{c}\text { Before } \\
\text { policy }\end{array}$ & $\begin{array}{c}\text { During } \\
\text { policy }\end{array}$ & $\begin{array}{c}\text { After } \\
\text { policy }\end{array}$ & $\begin{array}{c}\text { Time Difference } \\
\text { During-Before After-During }\end{array}$ \\
\hline
\end{tabular}

\section{A. Treated regions}

$\begin{array}{lcccccc}\text { age 50-54 } & 5.94 & 29.89 & 15.17 & & 23.95 & -14.72 \\ & {[6093]} & {[21910]} & {[8571]} & & (.43) & (.50) \\ \text { age 46-49 } & 4.13 & 4.19 & 5.35 & & 0.06 & 1.16 \\ & {[9511]} & {[17131]} & {[9680]} & & (.26) & (.28) \\ \text { Age difference: } & 1.81 & 25.70 & 9.82 & \text { DiD: } & 23.89 & -15.88 \\ & (.37) & (.35) & (.45) & & (.50) & (.57)\end{array}$

B. Control regions

$\begin{array}{cccccc}\text { age 50-54 } & 3.88 & 7.76 & 11.91 & 3.87 & 4.15 \\ & {[23690]} & {[54902]} & {[28286]} & (.17) & (.22) \\ \text { age 46-49 } & 3.23 & 4.62 & 6.12 & 1.39 & 1.50 \\ & {[35111]} & {[64024]} & {[33167]} & (.13) & (.16)\end{array}$

$\begin{array}{lllllll}\text { Age difference: } & 0.65 & 3.14 & 5.79 & \text { DiD: } & 2.48 & 2.65 \\ & (.16) & (.14) & (.23) & & (.21) & (.27)\end{array}$

$\begin{array}{llc}\text { DiDiD: } & 21.41 & -18.53 \\ & (.55) & (.63)\end{array}$

Notes: $\quad$ Share of spells lasting longer than 12 months * 100; standard error in parentheses; number of observations in brackets.

Source: Own calculations, based on Austrian Social Security data. 


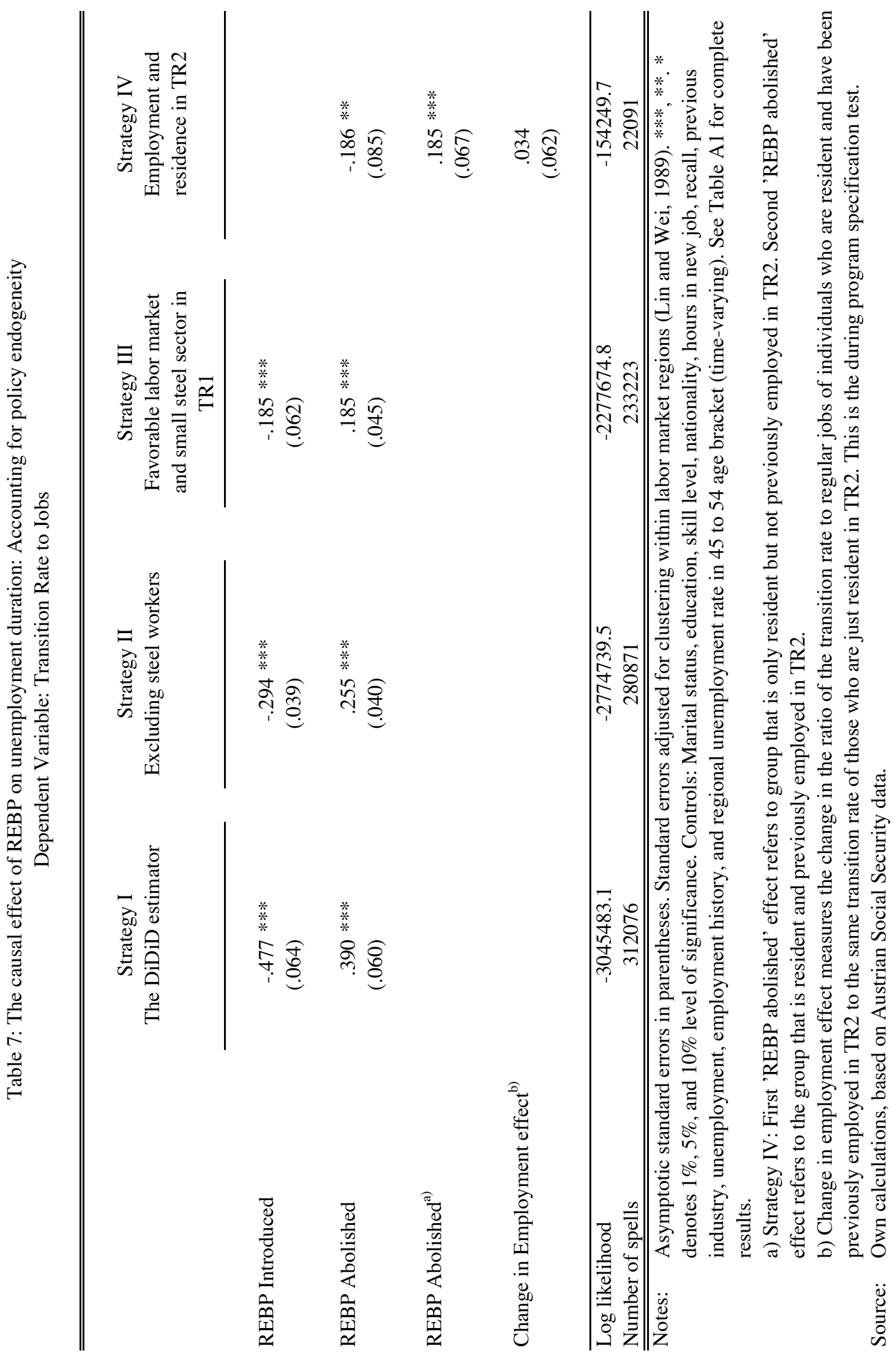


Table 8: The effect of benefit entitlement on the risk of long-term unemployment Non-steel workers, aged 50 or older, resident in TR2

\begin{tabular}{lcccc}
\hline \hline Residence / year & $\begin{array}{c}\text { Before } \\
\text { policy }\end{array}$ & $\begin{array}{c}\text { During } \\
\text { policy (I) }\end{array}$ & $\begin{array}{c}\text { During } \\
\text { policy (II) }\end{array}$ & $\begin{array}{c}\text { After } \\
\text { policy }\end{array}$ \\
\hline & & & & \\
Resident and employed & 5.33 & 16.77 & 25.36 & 11.60 \\
& {$[2948]$} & {$[5312]$} & {$[3225]$} & {$[3536]$} \\
& $\mathrm{N}$ & $\mathrm{T}$ & $\mathrm{T}$ & $\mathrm{N}$ \\
Just resident & 6.74 & 17.27 & 21.05 & 13.87 \\
& {$[1351]$} & {$[2756]$} & {$[1601]$} & {$[1918]$} \\
& $\mathrm{N}$ & $\mathrm{T}$ & $\mathrm{N}$ & $\mathrm{N}$ \\
Employment effect & -1.41 & -.50 & 4.31 & -2.27 \\
& $(.80)$ & $(.88)$ & $(1.27)$ & $(.96)$ \\
DiD estimate: & & & & \\
& & $(1.19)$ & $(1.55)$ & $(1.59)$ \\
\hline \hline
\end{tabular}

\footnotetext{
Notes: $\quad$ Share of spells lasting longer than 12 months * 100; standard error in parentheses; number of observations in brackets. $\mathrm{N}=$ Not eligible for extended benefis (REBP), $\mathrm{T}=$ =eligible for extended benefits (REBP)

Source: Own calculations, based on Austrian Social Security data.
} 
Table 9: Simulations of the effect of REBP on expected unemployment duration (measured in weeks)

Reference $^{\text {a) }}$

REBP

Strategy I $\quad-.477$

Strategy II $\quad-.294$

Strategy III $\quad-.185$

Strategy IV $\quad-.186$
18.9

52.7

33.8

.189

178.9

36.4

17.5

.098

92.8

28.7

9.8

.055

52.1

28.8
Increase in percent of Control

Notes: $\quad$ Strategy I: Entire sample; Strategy II: Excluding steel workers; Strategy III: Excluding TR2 residents and steel workers; Strategy IV: TR2 residents, aged 50 or older, non-steel workers. a) Married, low education, blue collar worker, Austrian, looking for part-time or unknown type of job, not recall, inflow in first quarter, from other industry, unemployed at least once, and with average values of the continuous covariates (unemployment duration in the past, work experience, and regional unemployment rate).

Source: Own calculations, based on Austrian Social Security data. 


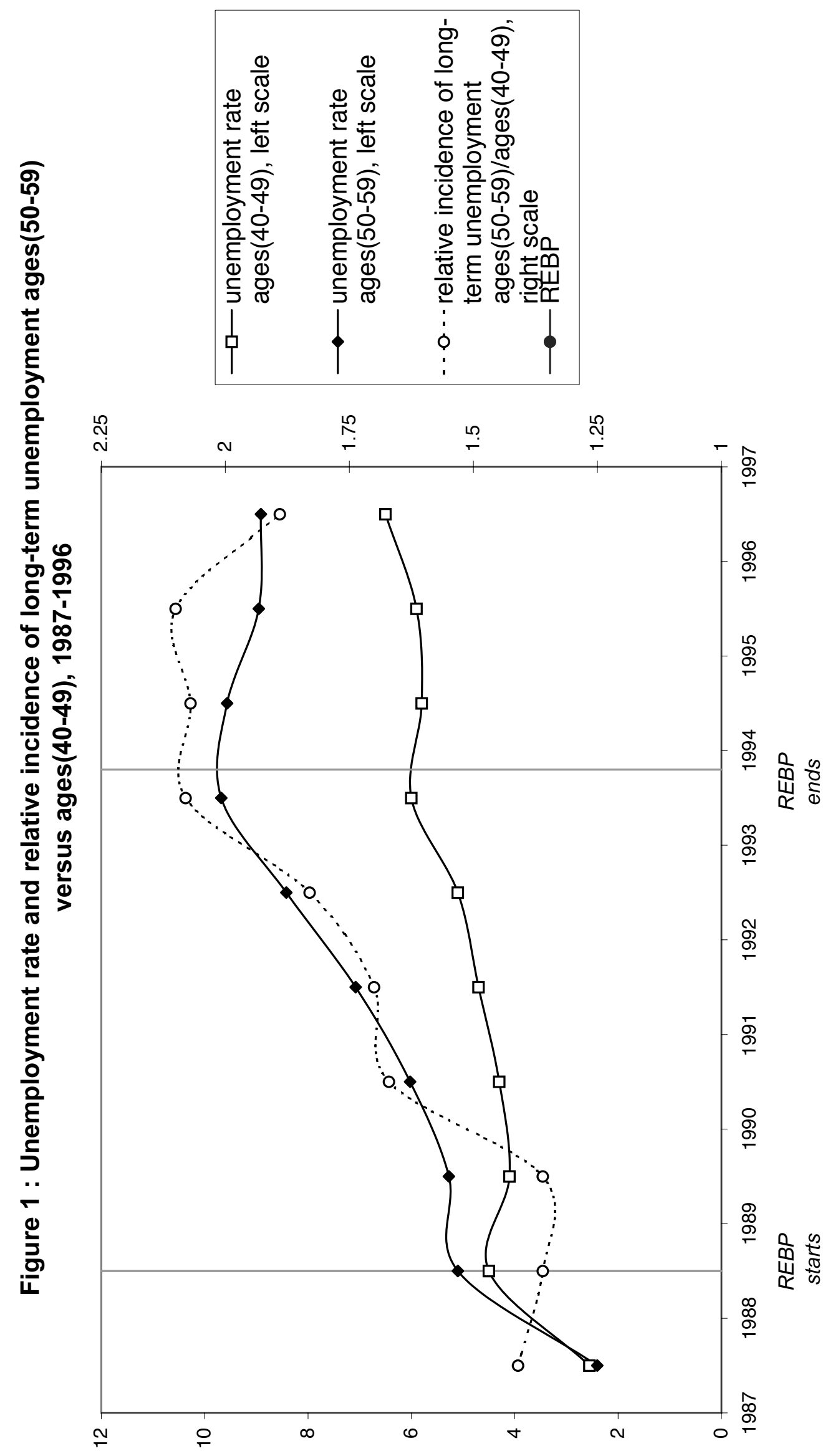




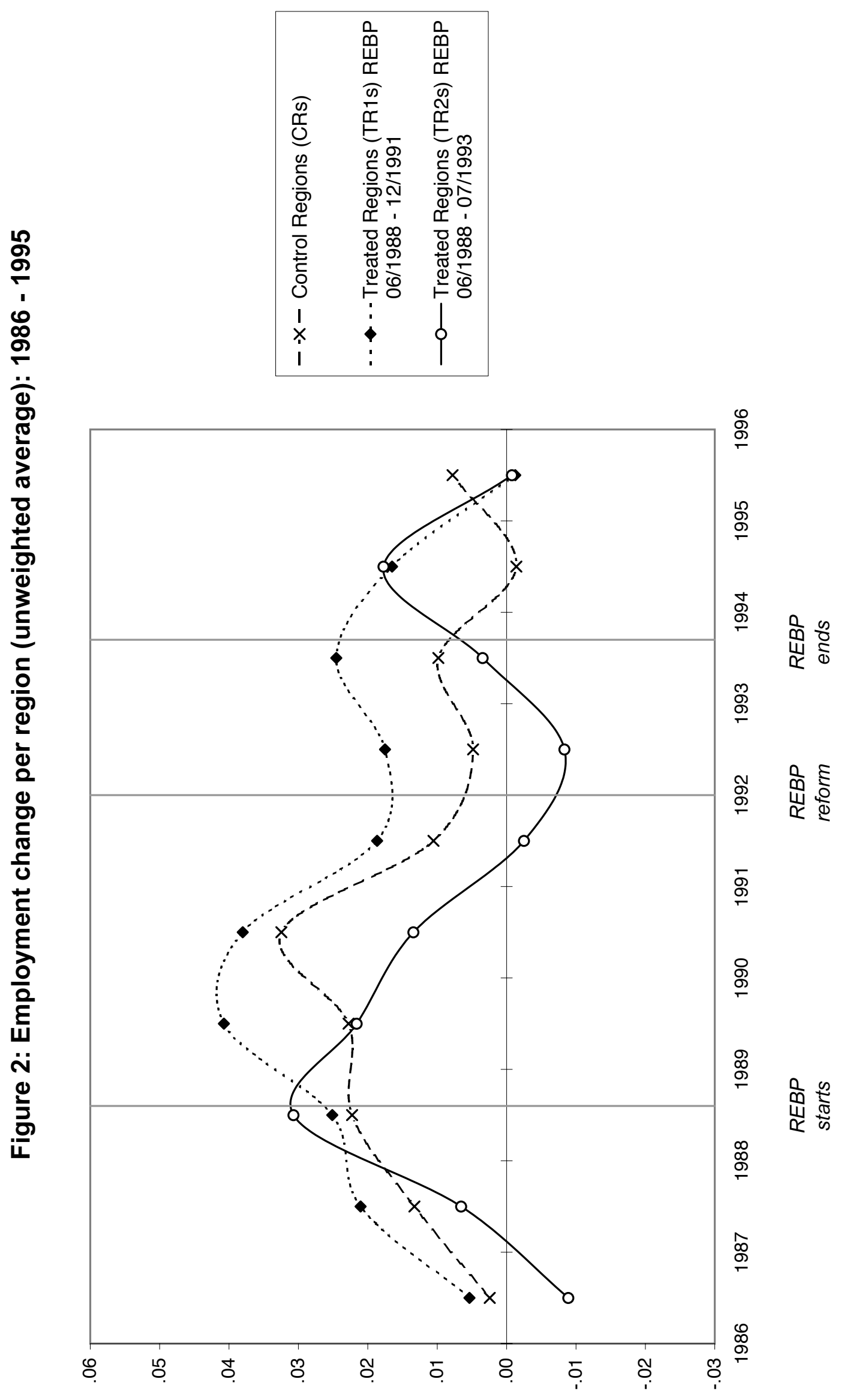




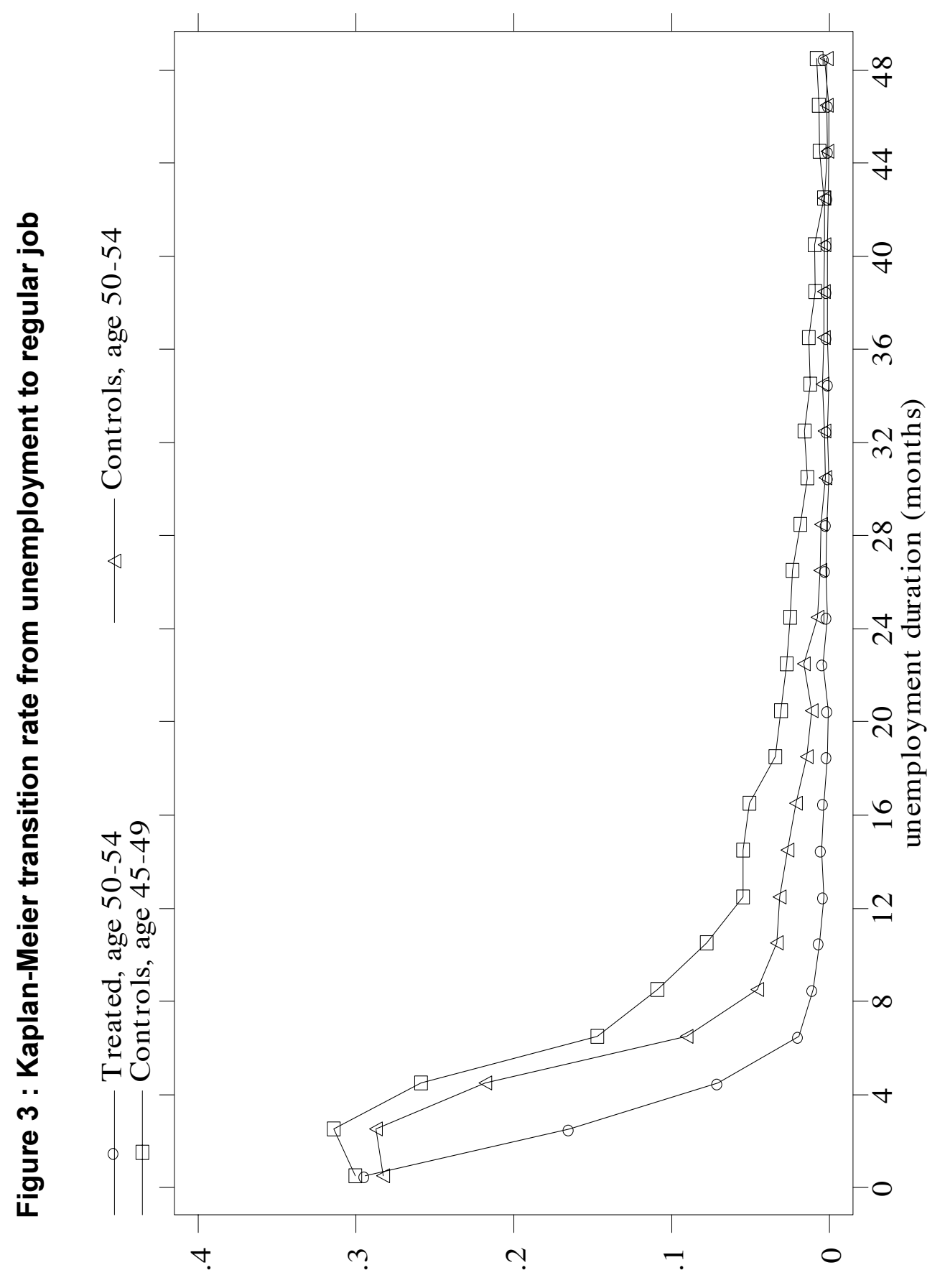




\begin{tabular}{|c|c|c|c|c|c|c|c|c|}
\hline & \multicolumn{2}{|c|}{ Strategy I } & \multicolumn{2}{|c|}{ Strategy II } & \multicolumn{2}{|c|}{ Strategy III } & \multicolumn{2}{|c|}{ Strategy IV } \\
\hline & Coeff. & Z-Value & Coeff. & Z-Value & Coeff. & Z-Value & Coeff. & $\underline{\text { Z-Value }}$ \\
\hline REBP introduced (During $*$ TR $*$ Age $50+$ ) & -.477 & $(-7.45)$ & -.294 & $(-7.47)$ & -.185 & $(-2.99)$ & & \\
\hline REBP abolished (After * TR * Age 50+) & .390 & $(6.53)$ & .255 & $(6.35)$ & .185 & $(4.06)$ & & \\
\hline During & .138 & $(7.73)$ & .132 & $(7.18)$ & .139 & (7.04) & & \\
\hline After & .011 & $(.82)$ & .006 & $(.42)$ & -.001 & $(-.05)$ & & \\
\hline TR & .005 & $(.20)$ & -.056 & $(-2.67)$ & -.090 & $(-2.31)$ & & \\
\hline Age $50+$ & -.109 & $(-9.27)$ & -.105 & $(-9.02)$ & -.107 & $(-9.09)$ & & \\
\hline TR $*$ Age $50+$ & -.012 & $(-.43)$ & .018 & $(.73)$ & .119 & $(3.55)$ & & \\
\hline During $* \mathrm{TR}$ & .059 & $(2.20)$ & .069 & $(2.60)$ & .065 & $(1.23)$ & & \\
\hline During * Age $50+$ & .005 & $(.25)$ & -.009 & $(-.55)$ & -.036 & $(-2.20)$ & & \\
\hline After $*$ TR & .016 & $(.64)$ & .045 & $(2.08)$ & .023 & $(1.53)$ & & \\
\hline After * Age $50+$ & .001 & $(.03)$ & -.009 & $(-.48)$ & -.051 & $(-2.64)$ & & \\
\hline During I & & & & & & & .019 & $(.39)$ \\
\hline During II & & & & & & & .172 & (3.23) \\
\hline After & & & & & & & .128 & $(2.51)$ \\
\hline Employment effect & & & & & & & -.025 & $(-.54)$ \\
\hline Change in 'Employment effect' & & & & & & & .034 & $(.55)$ \\
\hline REBP abolished for group 'just resident' & & & & & & & -.186 & $(-2.18)$ \\
\hline REBP abolished for group 'resident and emp & ed' & & & & & & .185 & $(2.78)$ \\
\hline \multicolumn{9}{|l|}{ Benefit extension 1989} \\
\hline 30 to 39 weeks & .004 & $(.34)$ & .010 & $(.74)$ & -.003 & $(-.23)$ & & \\
\hline 30 to 52 weeks & -.050 & $(-2.26)$ & -.027 & $(-1.63)$ & .015 & $(.89)$ & & \\
\hline \multicolumn{9}{|l|}{ Marital status (single) } \\
\hline married or cohabitant & .185 & $(18.63)$ & .190 & $(18.46)$ & 197 & (17.09) & .154 & $(4.26)$ \\
\hline separated & .020 & $(1.66)$ & .007 & $(.57)$ & .004 & $(.25)$ & .090 & (2.46) \\
\hline \multicolumn{9}{|l|}{ Education (low) } \\
\hline medium & -.020 & $(-2.00)$ & -.019 & $(-1.70)$ & -.018 & $(-1.39)$ & -.016 & $(-.80)$ \\
\hline high & -.162 & $(-6.51)$ & -.161 & $(-6.55)$ & -.173 & $(-6.04)$ & .027 & (.36) \\
\hline Blue collar & .682 & (33.23) & .706 & $(33.65)$ & .715 & (28.95) & .695 & (13.48) \\
\hline Foreign & .021 & $(1.44)$ & .004 & $(.23)$ & .006 & $(.33)$ & .003 & $(.06)$ \\
\hline Looking for a full time position & -.043 & $(-2.66)$ & -.063 & $(-3.83)$ & -.075 & $(-3.98)$ & -.059 & $(-2.21)$ \\
\hline Recall & .267 & $(17.11)$ & .272 & $(17.25)$ & .265 & $(14.59)$ & .375 & (11.59) \\
\hline \multicolumn{9}{|l|}{ Industry (other) } \\
\hline steel & -.131 & $(-3.50)$ & & & & & & \\
\hline electronic machines & -.125 & $(-4.92)$ & -.155 & $(-5.79)$ & -.135 & $(-4.89)$ & -.302 & $(-3.03)$ \\
\hline small machines & -.166 & $(-2.67)$ & -.180 & $(-2.86)$ & -.185 & $(-2.63)$ & -.064 & $(-.17)$ \\
\hline other manufacturing & -.021 & $(-.96)$ & -.033 & $(-1.38)$ & -.026 & $(-.92)$ & -.116 & $(-1.84)$ \\
\hline mining & .087 & $(1.93)$ & .083 & $(1.64)$ & .040 & $(.74)$ & .158 & $(1.35)$ \\
\hline construction & .222 & (14.41) & .238 & $(15.53)$ & .245 & (13.72) & .215 & $(7.07)$ \\
\hline tourism & -.041 & $(-2.31)$ & -.042 & $(-2.22)$ & -.030 & $(-1.40)$ & -.161 & $(-3.08)$ \\
\hline \multicolumn{9}{|l|}{ Inflow quarter (I) } \\
\hline II & -.020 & $(-1.27)$ & -.031 & $(-1.72)$ & -.019 & $(-.97)$ & -.113 & $(-1.85)$ \\
\hline III & -.064 & $(-4.24)$ & -.093 & $(-5.42)$ & -.093 & $(-4.92)$ & -.061 & $(-1.21)$ \\
\hline IV & -.350 & $(-15.45)$ & -.367 & $(-15.81)$ & -.361 & $(-13.27)$ & -.402 & $(-10.59)$ \\
\hline \multicolumn{9}{|l|}{ Unemployment history } \\
\hline not unemployed & -.436 & $(-27.82)$ & -.427 & $(-24.86)$ & -.400 & $(-23.23)$ & -.804 & $(-12.78)$ \\
\hline unemployment duration (years) & -.106 & $(-29.52)$ & -.109 & $(-27.71)$ & -.103 & $(-24.72)$ & -.146 & $(-15.26)$ \\
\hline Work experience (years) & -.017 & $(-13.44)$ & -.015 & $(-11.55)$ & -.012 & $(-10.07)$ & -.034 & $(-8.64)$ \\
\hline Unemployment rate in region (\%) & -6.406 & $(-15.65)$ & -5.872 & $(-13.33)$ & -6.082 & $(-10.69)$ & -5.530 & $(-9.36)$ \\
\hline Log likelihood & \multicolumn{2}{|c|}{-3045483.10} & \multicolumn{2}{|c|}{-2774739.50} & \multicolumn{2}{|c|}{-2277674.80} & \multicolumn{2}{|c|}{-154249.67} \\
\hline Number of spells & \multicolumn{2}{|c|}{312076} & \multicolumn{2}{|c|}{280871} & \multicolumn{2}{|c|}{233223} & \multicolumn{2}{|c|}{22091} \\
\hline
\end{tabular}

Notes: a) Benefit extension coefficients are not identified because the sample is restricted to those living in entitled regions, aged 50 or older.

b) Sample restricted to non-steel individuals. 
Table A2. Means and standard deviations

\begin{tabular}{|c|c|c|c|c|}
\hline & Strategy I & Strategy II & Strategy III & Strategy IV \\
\hline & Mean Std. Dev. & Mean Std. Dev. & Mean Std. Dev. & Mean Std. Dev. \\
\hline \multicolumn{5}{|l|}{ Benefit extension 1989} \\
\hline 30 to 39 weeks & .338 & .344 & .344 & .000 \\
\hline 30 to 52 weeks & .323 & .312 & .307 & .000 \\
\hline \multicolumn{5}{|l|}{ Marital status (single) } \\
\hline married or cohabitant & .789 & .790 & .788 & .827 \\
\hline separated & .111 & .109 & .109 & .092 \\
\hline \multicolumn{5}{|l|}{ Education (low) } \\
\hline medium & .412 & .403 & .403 & .375 \\
\hline high & .011 & .011 & .012 & .009 \\
\hline Blue collar & .849 & .856 & .852 & .870 \\
\hline Foreign & .110 & .110 & .112 & .095 \\
\hline Looking for a full time position & .267 & .261 & .246 & .314 \\
\hline Recall & .391 & .422 & .421 & .413 \\
\hline \multicolumn{5}{|l|}{ Industry (other) } \\
\hline steel & .100 & .000 & .000 & .000 \\
\hline electronic machines & .033 & .037 & .031 & .071 \\
\hline small machines & .002 & .002 & .003 & .001 \\
\hline other manufacturing & .063 & .070 & .064 & .109 \\
\hline mining & .015 & .017 & .014 & .030 \\
\hline construction & .439 & .487 & .496 & .428 \\
\hline tourism & .120 & .133 & .140 & .089 \\
\hline \multicolumn{5}{|l|}{ Inflow quarter (I) } \\
\hline II & .139 & .128 & .129 & .122 \\
\hline III & .132 & .125 & .124 & .125 \\
\hline IV & .421 & .432 & .432 & .435 \\
\hline \multicolumn{5}{|l|}{ Unemployment history } \\
\hline not unemployed & .220 & .188 & .181 & .250 \\
\hline unemployment duration (years) & $1.224(1.284)$ & $1.304(1.299)$ & $1.325(1.305)$ & $1.139(1.266)$ \\
\hline Work experience (years) & $16.225(4.706)$ & $16.173(4.641)$ & $16.121(4.630)$ & $16.832(4.665)$ \\
\hline Unemployment rate in region $(\%)$ & $4.294(2.398)$ & $4.212(2.299)$ & $4.054(2.161)$ & $5.099(2.740)$ \\
\hline Number of spells & 312076 & 280871 & 233223 & 22091 \\
\hline
\end{tabular}


REBP

REBP introduced (During * TR * Age 50+)

REBP abolished (After * TR * Age 50+)

During

During I

During II

After

TR

TR1

TR2

TR2 Residence

TR2 Employment

Age 50+

TR * Age 50+

During * TR

During * Age 50+

After $*$ TR

After * Age 50+

Benefit extension 1989

30 to 39 weeks

30 to 52 weeks

Marital status

$$
\begin{aligned}
& \text { single } \\
& \text { married } \\
& \text { separated }
\end{aligned}
$$

Education

low

medium

high

Blue collar

Foreign

Looking for a full time position

Recall

Industry

other

steel

electronic machines

small machines

other steel

mining

construction

tourism

Unemployment history

Not unemployed

Unemployment duration (years)

Work experience (years)

Unemployment rate in region (\%)
Regional extended benefit program: benefits extended from 30 weeks to 209 weeks for individuals age 50 or older, living in TR, from 1988.06 to 1993.07

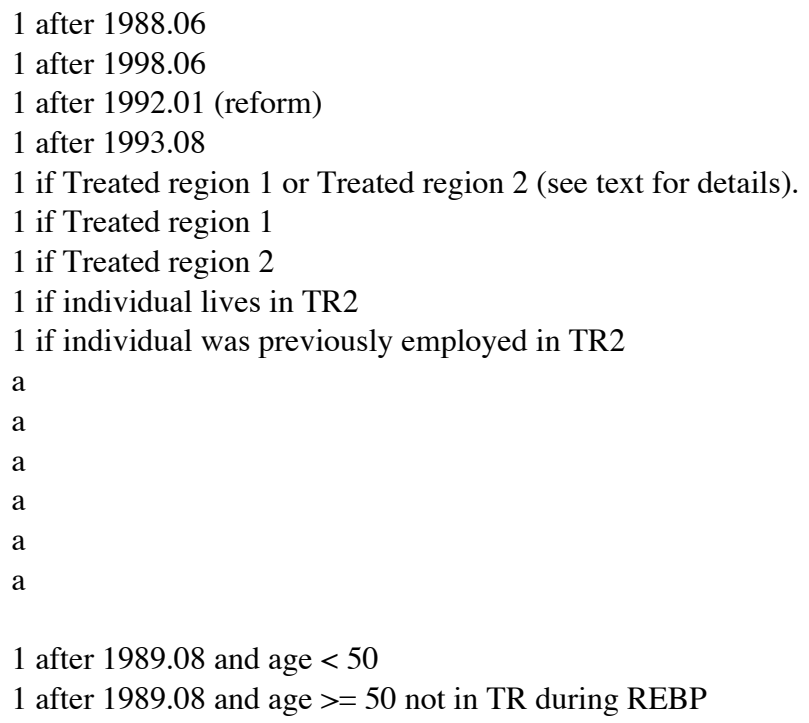

a

a

a

9 years of schooling (mandatory) apprenticeship vocational, university degree a

1 if individual indicates that she or he is looking for a $100 \%$ position 1 if employer will re-hire the person

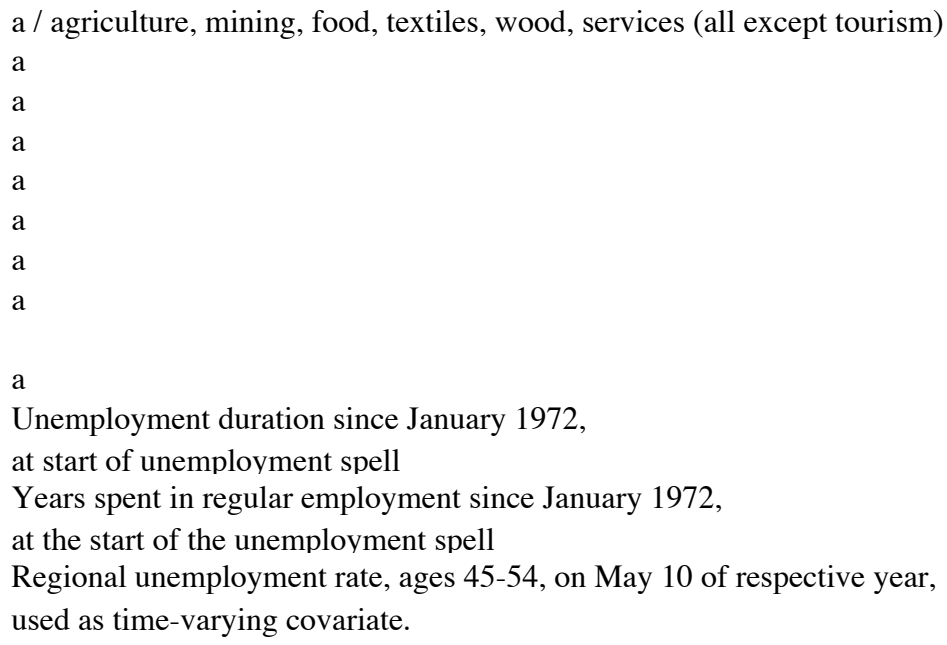
used as time-varying covariate.

Note: a. Variable is a dummy that takes the value 1 if the condition is fulfilled. 